\title{
Electrospun polymer nanofibers: The booming cutting edge technology
}

\author{
Prasanth Raghavan ${ }^{a}$, Du-Hyun Lim ${ }^{\mathrm{a}}$, Jou-Hyeon Ahn ${ }^{\mathrm{a}, *}$, Changwoon Nah $^{\mathrm{b}}$, David C. Sherrington ${ }^{\mathrm{c}}$, \\ Ho-Suk Ryu ${ }^{\mathrm{d}}$, Hyo-Jun Ahn ${ }^{\mathrm{d}}$ \\ ${ }^{a}$ Department of Chemical and Biological Engineering and Engineering Research Institute, Gyeongsang National University, 900, Gajwa-dong, Jinju 660-701, Republic of Korea \\ ${ }^{b}$ Department of Polymer-Nano Science and Technology, Chonbuk National University, 664-14 Duckjin-dong, Jeonju 561-756, Republic of Korea \\ ${ }^{\mathrm{c}}$ Department of Pure and Applied Chemistry, University of Strathclyde, 295 Cathedral Street, Glasgow G1 1XL, United Kingdom \\ ${ }^{\mathrm{d}}$ School of Nano and Advanced Materials Engineering, Gyeongsang National University, 900, Gajwa-dong, Jinju 660-701, Republic of Korea
}

\section{A R T I C L E I N F O}

\section{Article history:}

Available online 3 September 2012

\section{Keywords:}

Electrospinning

Nanofiber

Nanofibrous mat

Separator

Polymer electrolyte

\begin{abstract}
A B S T R A C $T$
Electrospinning has been recognized as a simple and efficient technique for the fabrication of ultrathin fibers from a variety of materials including polymers, composite and ceramics. Significant progress has been made throughout the past years in electrospinning and the resulting fibrous structures have been exploited in a wide range of potential applications. This article reviews the state-of-art of electrospinning to prepare fibrous electrode materials and polymer electrolytes based on electrospun membranes in the view of their physical and electrochemical properties for the application in lithium batteries. The review covers the electrospinning process, the governing parameters and their influence on fiber or membrane morphology. After a brief discussion of some potential applications associated with the remarkable features of electrospun membranes, we highlight the exploitation of this cutting edge technology in lithium batteries. Finally the article is concluded with some personal perspectives on the future directions in the fascinating field of energy storage.
\end{abstract}

() 2012 Elsevier Ltd. All rights reserved.

\section{Introduction}

Unlike conventional fiber spinning techniques (wet spinning, dry spinning, melt spinning, gel spinning), which are capable of producing polymer fibers with diameters down to the micrometer range, electrostatic spinning or electrospinning is a process capable of producing polymer fibers in the submicron to nanometer diameter range. Electrospinning is a simple and versatile method for generating ultrathin fibers from a wide range of materials that include polymers, composites and ceramics. It is the most promising and rapid process to produce continuous nanofibers (aspect ratio $>1000$ ) [1-5]. The first patent on electrospinning technique was published as early as in 1934 [6]. Electrospinning of polymeric fibers gained much attention in the past decade not only due to its versatility in spinning a wide variety of polymeric fibers but also due to its consistency in producing fibers in the nano-range with uniform morphology. Interest in this mature technology was revived in the 1980 s when it was demonstrated that the process could be used to fabricate ultrafine fibers and fibrous structures of various polymers with diameters down to submicrons or nanometers. Renekar and Chun, who revived interest in this technology in the early 1990s, have shown the possibility of electrospinning a wide range of polymer solutions in 1996 [7]. The fibers prepared by

\footnotetext{
* Corresponding author. Tel.: +82 55772 1784; fax: +82 557721789 .

E-mail address: jhahn@gnu.ac.kr (J.-H. Ahn).
}

electrospinning have extremely high specific surface to volume ratio $\left(6.75 \times 10^{6}\right.$ to $\left.7.7 \times 10^{7}\right)$ due to the nano to submicron fiber diameter [8]. The non-woven mats or membranes prepared by this method can be highly porous with excellent pore interconnectivity. Several methods have been developed to fabricate nanofibers, such as templating $[9,10]$, phase separation [11], melt blown [12], self assembly [13-15], and electrospinning [16-18].

Various synthetic polymers such as PAN [19], PMMA [20] and PEO [21] have been successfully electrospun into ultrafine fibers mostly in solution and some in melt form. The electrospun membranes (ESMs) find various applications in composite reinforcement, filtration systems, tissue engineering, medical prostheses, electromagnetic shielding and liquid crystal devices [17]. Even natural polymers like silks from the Nephila clavipes spider [22] and the Bombyx mori silkworm [22-26], chitin [27], etc. have also been electrospun. They are suitable for filtration and biomedical applications like wound dressing/healing and scaffolds for tissue engineering. The most important feature of electrospinning may lie in the fabrication of nano-tubules/nano-fibrils of conducting polymers, metals, semiconductors, carbon, etc. [17].

The objectives of this article are to briefly discuss the electrospinning process and the governing parameters which influence the fiber morphology, to demonstrate the potential of this technique to produce fibers with engineered secondary structures, morphologies and functionalities, to address the issues related to the organization of fibers into hierarchical assemblies, and finally 


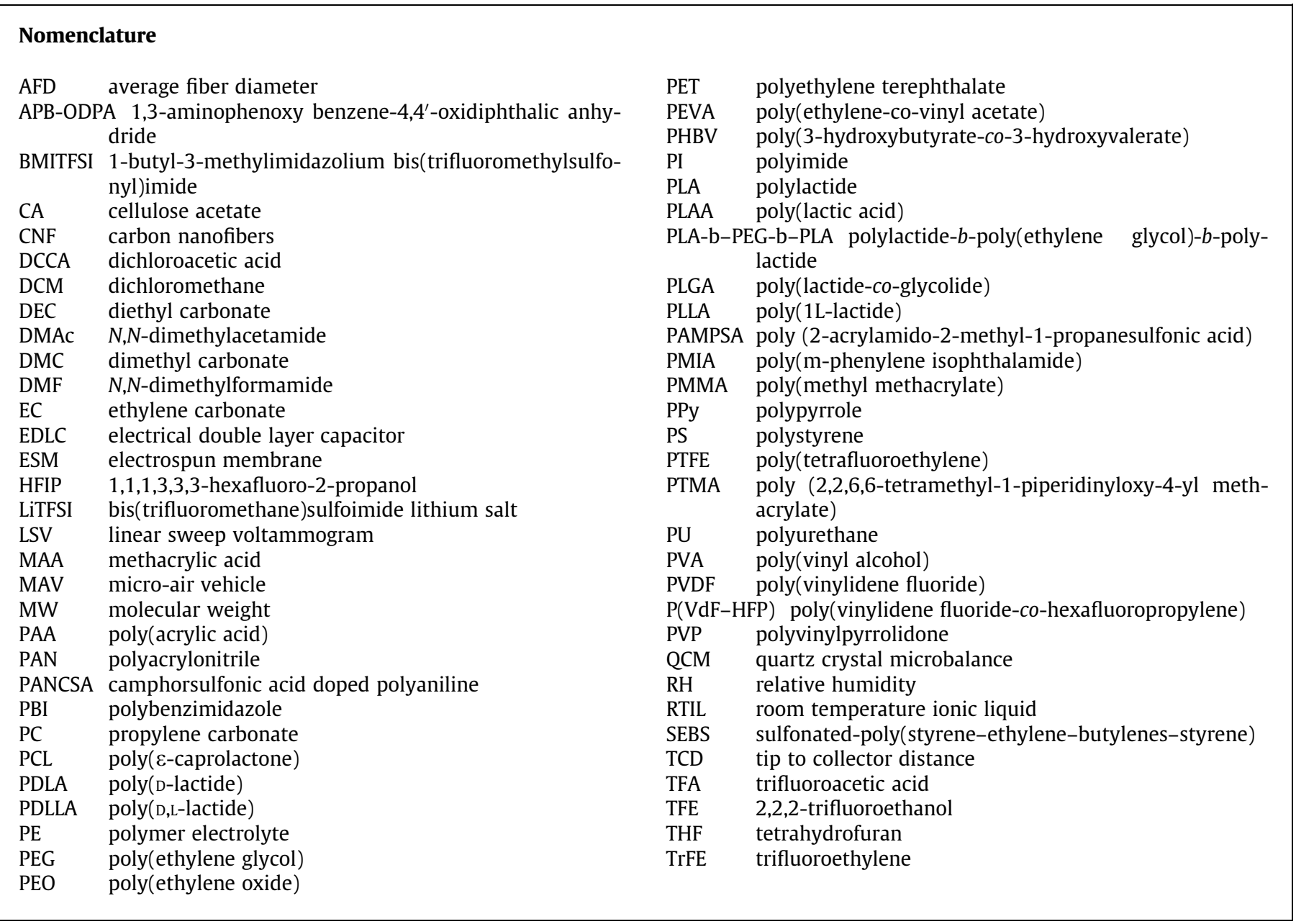

to discuss the unique features and potential applications of electrospun fibers. The body of the article is organized with a brief introduction and history of electrospinning, the process and theory of electrospinning, the governing parameters and their influence on the morphology and properties of the fibers, some recent developments related to the alignment and orientation of fibers, the potential application highlighted in energy storage, and finally the personal perspective on the future of the technique.

\section{History of electrospinning}

The electrospinning technique has been generally considered as the variant of the electrostatic spraying or electrospraying process [28-31]. Both of these techniques involve using a high voltage to induce the formation of a liquid jet. In the electrospray process, small droplets or particles are formed as a result of the varicose break-up of the electric jet that is often present with a solution of low viscosity. In electrospinning, a solid fiber is generated as the electrified jet of viscous polymer solution is continuously stretched due to the electrostatic repulsion between the surface charges and evaporation of solvent. Until 1933, this technique had been known as electrostatic spinning, and there were only a few publications dealing with its use in the fabrication of thin fibers [32-34]. In 1934, Formhals patented his first invention relating to the process and the apparatus for producing artificial filaments using electric charges [6]. Though the method of producing artificial threads using an electric field had been experimented on for a long time, it had not gained importance. Formhals spinning setup consisted of a movable thread collecting device in the form of a spinning drum similar to the one in the conventional spinning, on which the threads were collected in a stretched state. However, the setup was capable of producing parallel threads onto the collection device in such a fashion that they can be unwound continuously. The main disadvantage of the spinning method designed by Formhals was that it was difficult to completely dry the fibers due to the short distance between the spinning zone and the collector. In 1939 he revised the disadvantages of the earlier setup by altering the distance between the spinneret and the collection device to get more drying time for the electrospun fibers and, he patented the method [35]. In 1940, Formhals developed a method for producing composite fiber webs from multiple polymer and fiber substrate by electrostatically spinning polymer fibers on a moving base substrate [36]. In the 1960s, Tylor initiated fundamental studies on the jet forming process. In this, Tylor studied the shape of the polymer droplet produced at the tip of the needle when an electric field is applied and showed that it is a cone shape and that the jets were ejected from the vertices of the cone [37]. This conical shape of the jet was later referred as the Tylor cone in subsequent literatures. By the detailed examination of different viscous fluids, Tylor determined that an angle of $49.3^{\circ}$ is required to balance the surface tension of the polymer fluids with the electrostatic force. In subsequent years researchers studied the relationship between the structural morphology and the process parameters and several studies have reported on the electrospinning of polymer solutions and melts [32-34].

Lorrondo and Manley [33,34] reported on the electrospinning of polypropylene and polyethylene from its melt, which have rela- 


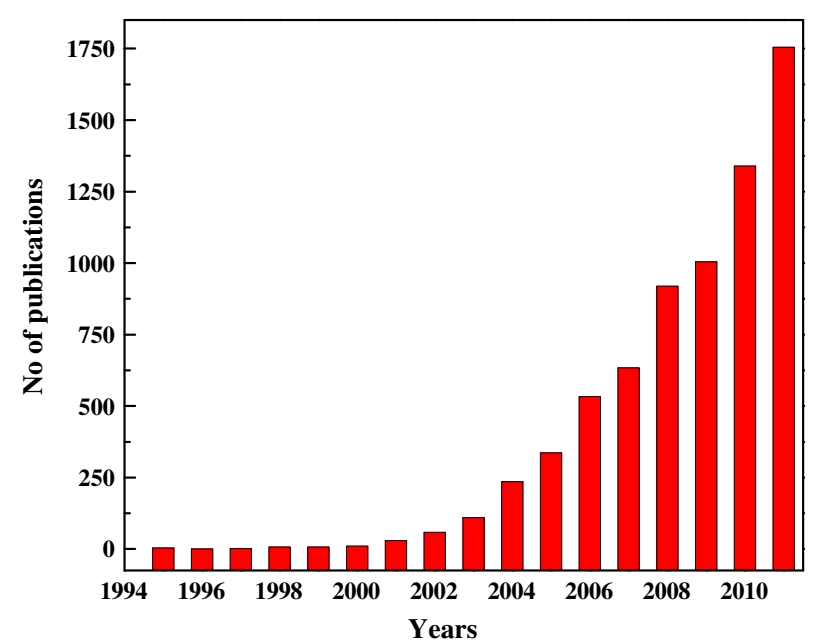

Fig. 1. The annual number of publications on the subject of electrospinning as provided by the search engine Scopus (keyword: electrospinning). For 2012, there are already 1400 publications before September.

tively larger diameters compared to the as-spun fibers from solution spinning. They studied the effect of melting temperature and applied voltage on fiber diameter. In the early 1990s, several research groups revived interest in this technique by demonstrating the fabrication of thin fibers from a broad range of organic polymers. By this point, the term electrospinning has been coined and is now widely used in the literature $[7,16,17,38]$. These timely demonstrations triggered a lot of experimental and theoretical studies related to electrospinning. It is notable that the number of publications in the field has been increasing exponentially in the past few years, on account of the remarkable simplicity, versatility and potential use of this technique. Research on nanofibers gained dynamic momentum due to the work of Doshi and Reneker [16]. Fig. 1 shows the annual number of publications on the subject of electrospinning as provided by the search engine of Scopus.

\section{Electrospinning theory and process}

In electrospinning, a high-voltage electric field is applied to a polymer fluid stream (solution or melt) through a thin nozzle by inducing free charges into the polymer fluid. These charged ions move in response to the applied electric field towards the electrode of the opposite polarity, thereby transferring tensile forces to the polymer fluid. Most charge carriers in organic solvents and polymers have lower mobilities and hence the charges are expected to move through a longer distance of the liquid only if given enough time. When the charge within the fluid reaches above the critical voltage, a fluid jet will erupt from the droplet at the tip of the needle, resulting in the formation of a Tylor cone. Because of the interaction between the jet and the external electric field and charge repulsion inside, the jet undergoes a bending or whipping instability to stretch it more thinly. The electrospinning jet travels towards the lower potential, which in most cases is a grounded collector called the target. As the jet travels in air, the solvent evaporates to leave behind the dry fiber which gets deposited on a collector as nano to submicron level fibers [16-18]. For low viscosity solutions the jet breaks up into droplets, while for high viscosity solutions it travels to the collector as fiber jet [37]. The researchers working on electrospinning have examined different polymer solutions ranging from natural to synthetic polymers or containing metallic oxides and ceramic particles. Some have simply opted for placing the solution holder and the needle vertically, letting the polymer fluid drop with the help of gravity and laying the col- lector underneath [39]. Some research groups keep the capillary at a tilted angle to control the flow $[40,41]$. In other cases, the capillary is clamped in a horizontal position and a syringe infusionwithdrawal pump is used to control the feed rate of the polymer solution. The pump is also used in the case of vertical spinning. The high voltage can be applied to the polymer fluid by either inserting the electrode in the polymer fluid or clamping the electrode of the power supply at the tip of the steel needle, if a syringe pump with a metal needle is used.

In most cases, the as-spun fibers deposit randomly on the target forming a non-woven fibrous mat. Fig. 2 shows the SEM image of a typical electrospun membrane prepared with $16 \mathrm{wt} \%$ solution of $\mathrm{P}(\mathrm{VdF}-\mathrm{HFP})$ in acetone/DMAc (7:3 wt/wt). With proper control of the processing parameters, fibrous membranes with porosities of $30-90 \%$ and pore size in the range of sub-micrometers to a few micrometers can be made. In the case of a melt the discharged jet solidifies when it travels through the air and is collected on the grounded target. Fig. 3 shows a typical laboratory electrospinning setup. It consists of a nozzle, a high voltage power supply, a barrel for polymer fluid, and a target for collecting the fibers. The main advantage of this top-down manufacturing process is its relatively low cost compared to that of most bottom-up methods and that the fibers or membranes are often uniform and continuous. Due to the inherent properties of the electrospinning process, which can control the deposition of polymer fibers onto the target substrate, fibers with complex and seamless three dimensional network morphologies can be formed. This technology offers the formation of nanoscale composite fibers from a mixture of rigid rod polymers, and use of flexible polymers is also feasible. The electrospun fibers can even be aligned to construct unique functional nanostructures such as nanotubes and nanowires. Fig. 4 shows the photograph of a spinning jet.

The parameters affecting electrospinning of polymer solutions are broadly classified as system, solution, process and ambient parameters. System parameters include the molecular weight and molecular weight distribution of the polymers and the architecture of the polymer, such as linear, branched or block copolymers. Polymer solution parameters include the solution concentration, solution viscosity, surface tension, temperature, electrical and thermal conductivity and dielectric constant. The solution parameters have the most significant influence in the electrospinning process and electrospun fiber morphology. The surface tension has a role partially in the formation of beads along the fiber axis. The viscosity of the solution and its electrical characteristics determine the extent of the elongation of the solution. This, in turn,

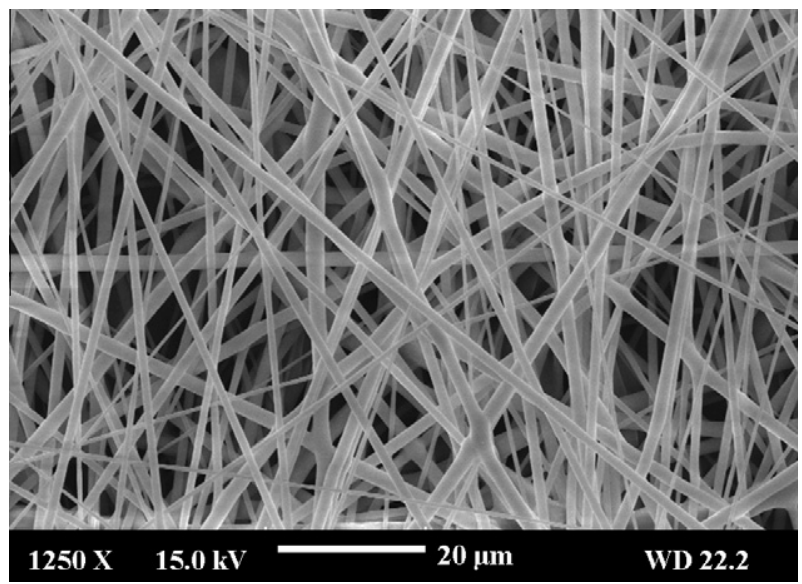

Fig. 2. FE-SEM image of $P(V d F-H F P)$ fibers electrospun from $16 \mathrm{wt} \%$ solution in a mixture of acetone/DMAc ( $7: 3 \mathrm{wt} / \mathrm{wt})$. 


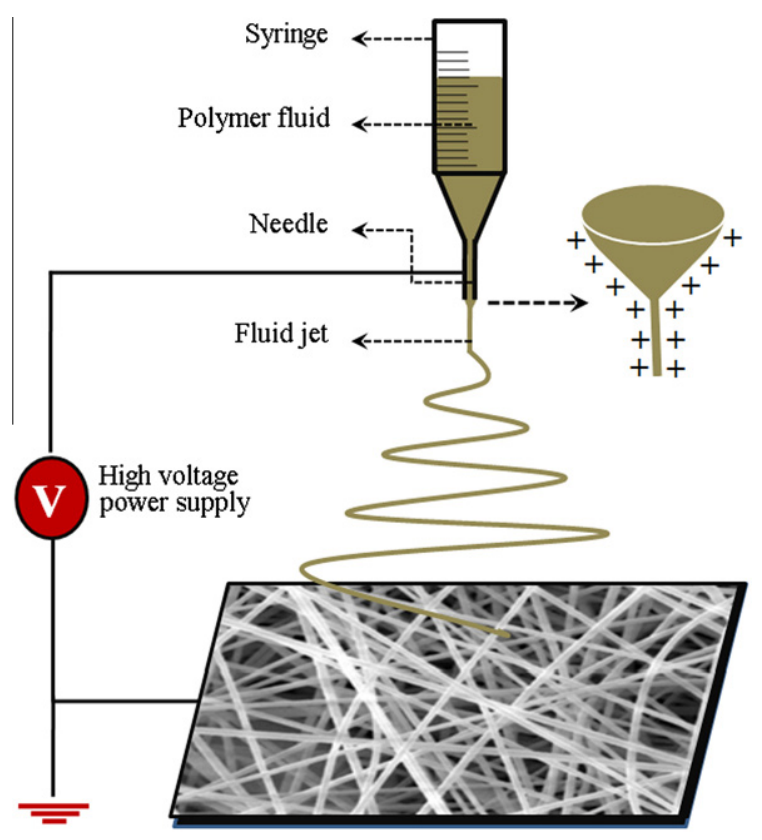

Fig. 3. Schematic representation of typical laboratory type electrospinning setup.

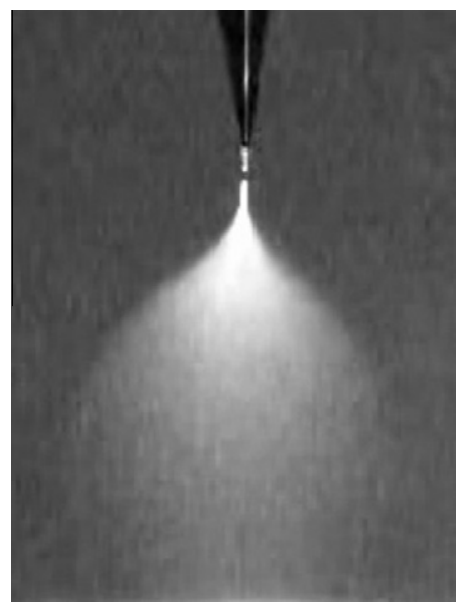

Fig. 4. Photograph illustrating the instability region of a liquid jet.

has an effect on the diameter of the electrospun fiber. The processing conditions include the applied voltage, flow rate, gap between the needle and target, type of collector, and its speed in the case of a dynamic type. Other processing conditions are the diameter of the needle and the ambient parameters including temperature, humidity and air velocity in the spinning chamber. These parameters have some influence on fiber morphology although they are less significant than the effect of the solution parameters.

\section{Parameter investigation}

There are many studies aimed at understanding the governing parameters in electrospinning. Theron et al. [42] have carried out a major work in this direction. Ideal targets for electrospun polymeric fiber are:

(i) consistent and controllable diameters;

(ii) defect-free or defect-controllable fiber surface; and

(iii) collectable continuous single and/or aligned fibers.

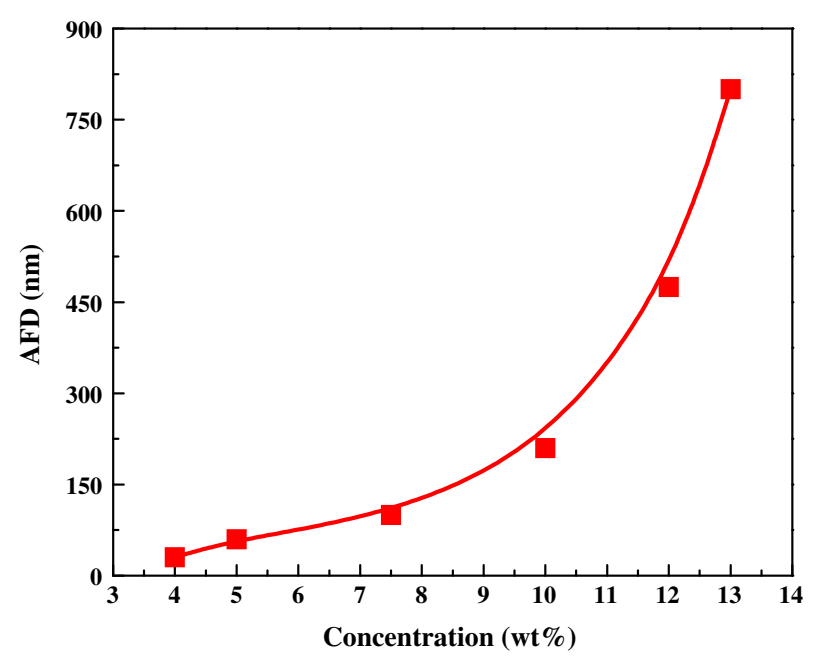

Fig. 5. AFD of electrospun fibers as a function of solution concentration.

These three targets are by no means easily achievable. The most important quantity related to electrospinning is the fiber diameter. Since fibers result from the solidification of fluid jets, the diameter depends primarily on jet sizes as well as on the polymer content in the jets. Higher concentration, which means higher viscosity, results in larger fiber diameter. Again, a higher voltage ejects more fluid in the jet, resulting in larger fiber diameter [43].

One of the challenges with electrospinning is that fiber diameter is seldom uniform. Demir et al. [43] obtained more uniform PU fibers at higher temperature $\left(70^{\circ} \mathrm{C}\right)$ than at room temperature. However, they did not compare the viscosities at the two temperatures [43]. Another problem is defect formation such as beads and pores occurring in the electrospun fibers. Higher concentration results in fewer beads. Doshi and Reneker [16] pointed out that by reducing the surface tension of a polymer solution, fibers could be obtained with fewer beads.

\subsection{Solution properties}

\subsubsection{Conductivity}

Polymers are mostly nonconductive, with the exception of a few dielectric materials, and charged ions in the polymer solution are highly influential in jet formation. The ions increase the charge carrying capacity of the jet, thereby subjecting it to higher tension with the applied electric field. Shin et al. found [44] a higher jet stability for PEO solution than glycerol, attributed to the higher conductivity of the PEO solution. More highly conducting polymer solutions may be easily collected in aligned form in electrospinning. Lee et al. [45] observed that the throughput increases with increasing electric conductivity of PS solutions. It has been reported that the throughput increases with salt concentration or conductivity of the polymer solution. Zong et al. [46] demonstrated the effect of ions on the morphology and fiber diameter of electrospun fibers by adding ionic salts. They found that by adding ionic salts to the polymer fluid, beadless fibers with relatively smaller diameters ranging from 200 to $1000 \mathrm{~nm}$ were produced.

\subsubsection{Solvent effects}

Son et al. [47] studied the effect of solution properties on electrospinning of PEO to observe that higher the dielectric constant of solvent, lower the fiber diameter. As the dielectric constant of the polymer fluid increases, the AFD decreases marginally. Solvent composition also affects fiber morphology. Lee et al. [45] studied the bead morphology of electrospun PS from a mixture of THF 
Table 1

Summary of ESMs prepared with different non-biodegradable polymer-solvent systems.

\begin{tabular}{|c|c|c|c|c|}
\hline Polymer & Solvent & Concentration & Remarks & Ref. \\
\hline PU & DMF & $2.5-17.7 \mathrm{wt} \%$ & & [43] \\
\hline Nylon 6, Nylon 12 & HFIP & $15 \mathrm{wt} \%$ & Effect on crystallization chain conformation & [54] \\
\hline PAN & DMF & $7.5-20 \mathrm{wt} \%$ & Initial approach for microfiber production; effect of $\mathrm{LiCl}$ & [55] \\
\hline PVDF & DMF & $30 \mathrm{wt} \%$ & & [58] \\
\hline \multirow[t]{3}{*}{ PS } & \multirow[t]{3}{*}{ THF } & \multirow[t]{3}{*}{$15,20,25 \mathrm{wt} \%$} & Effect of humidity, MW on surface morphology & [45] \\
\hline & & & Aligned continuous fibers & [63] \\
\hline & & & Study of bead morphology & [64] \\
\hline Polyaniline (AMPSA doped) & DCCA & & Electroless Ni deposition on fibers & [69] \\
\hline PMMA & Chloroform & $15,20,25 \mathrm{wt} \%$ & Continuous, aligned fibers & [70] \\
\hline Copolymer of PVDF/trifluoroethylene & DMF & $10,16,20 w t \%$ & MAV skin & [71] \\
\hline PBI & DMAC & $20 \mathrm{wt} \%$ & Deriving carbon nanofiber by graphitization & [72] \\
\hline PET & TFA & $0.2 \mathrm{~g} / \mathrm{ml}$ & Surface engineering for blood vessel engineering & [73] \\
\hline Poly(2-acrylamido-2-methyl-1-propane sulfonic acid) (PAMPSA) & Ethanol/water & $6 \mathrm{wt} \%$ & Effect of electric current on processing & [74] \\
\hline
\end{tabular}

Table 2

Summary of ESMs prepared with different biodegradable polymer-solvent systems.

\begin{tabular}{|c|c|c|c|c|}
\hline Polymer & Solvent & Concentration & Remarks & Ref. \\
\hline N. clavipes spider & HFIP & $0.23-1.2 \%$ & Structure and morphology study & {$[22]$} \\
\hline Silk ibroin/chitosan & Formic acid & & Effect of chitosan on morphology/conformation & {$[24]$} \\
\hline B. mori silk & HFIP & $0.74 \%$ & $\begin{array}{l}\text { Nanofibers of diameter like sub-fibers of natural silk } \\
\text { produced }\end{array}$ & {$[26,59]$} \\
\hline Chitin, chitosan & HFIP & & Deacetylation of chitin nanofibers & [27] \\
\hline PVA & Water & {$[\eta] C>5$} & Effect of MW & {$[48]$} \\
\hline PVP & & & Uniaxially aligned fibers & [56] \\
\hline $\mathrm{PVA} / \mathrm{CA}$ & Water/DMAc & $10 \mathrm{wt} \%$ & Biodegradable mats, multi-jet electrospinning & [57] \\
\hline Gelatin & TFE & $5-12.5 w t \%$ & Mechanical characterization & {$[60]$} \\
\hline \multirow[t]{6}{*}{ PEO } & Water & $1-7 w t \%$ & General studies on process-morphology relations & {$[16]$} \\
\hline & Ethanol/water (40/60) & $2-6 w t \%$ & Morphological studies & {$[42]$} \\
\hline & Ethanol/water (7/2) & $\begin{array}{l}2 \text { wt\%; } 3 \text { (chloroform), } 4 \text { (ethanol), } 5 \text { (DMF), } \\
7 \text { (water) wt\% }\end{array}$ & Effect of viscosity, filler on fiber morphology & {$[43]$} \\
\hline & & & Effects of solution properties, polyelectrolyte & {$[47]$} \\
\hline & Water/ethanol (60/40) & $2 \mathrm{wt} \%$ & Needle-less magnetic spinning & [61] \\
\hline & Water/ethanol (50/50) & $10 \mathrm{wt} \%$ & Oriented nanofibers on planar surfaces & [62] \\
\hline PAA/PVA & Water & $12.5 \mathrm{wt} \%, 10 \mathrm{wt} \%$ & Nanofiber coated quartz crystal as $\mathrm{NH}_{3}$ sensor & {$[65]$} \\
\hline PCL/Gelatin & TFE & $10 \%(w / v)$ & Bicomponent fiber via coaxial elecrtrospinning & {$[66]$} \\
\hline PDLA & DMF/chloroform & $14 \%(w / v)$ & Drug delivery & [67] \\
\hline PLLA & DCM/DMF & & $\begin{array}{l}\text { Morphological study - effect of solution concentration on } \\
\text { membrane morphology }\end{array}$ & {$[68]$} \\
\hline
\end{tabular}

and DMF. It was found that bead concentration depends on the DMF content; half hollow sphere structures appeared in fibers from PS in THF only.

\subsubsection{Polymer molecular weight, solution concentration, viscosity and surface tension}

Koski et al. [48] investigated the effect of the molecular weight of PVA on its electrospun fiber structure. Ultrafine PVA fibers were obtained for an intrinsic viscosity $[\eta] C>5$. The cross-section of PVA fibers was circular-shaped at $[\eta] C>9$ and flat at $[\eta] C>10$. Increase in solution concentration/viscosity results in increased fiber diameter (Fig. 5) [16,42,49-53]. Demir et al. [43] derived a power relationship between the AFD and concentration.

AFD $=(\text { Concentration })^{3}$

Tables 1 and 2 shows the summary of ESM prepared with different biodegradable and non-biodegradable polymer-solvent systems. Deitzel et al. [75] electrospun PEO; below $4 \mathrm{wt} \%$ concentration, they obtained a mixture of fibers and droplets while above $10 \mathrm{wt} \%$, spinning was prohibited by high viscosity. They observed that the AFD is related to the solution concentration through a power law relationship with exponent of about 0.5 . Near $8 \mathrm{wt} \%$, second population fibers with diameters about one third of that of the primary population fibers are produced due to fiber splaying. Fig. 6 shows the SEM images of PAN prepared with different solution concentrations.

Brune and Bicerano [76] observed that beads are less likely to form using more viscous solutions. They also observed that lower surface tension favors bead-free filaments. Fig. 7 shows the bead morphology with increasing solution concentration. Drew et al. [77] had demonstrated through a study on $\mathrm{TiO}_{2}$ filled PEO that above a critical polymer concentration, the viscosity effect on fiber morphology was the same whether the viscosity was due to polymer or some other material. Lee et al. [45] reported increasing bead aspect ratio with increasing concentration for electrospun PS. Above $15 \mathrm{wt} \%$, fibers without beads formed due to high viscosity. They also found the critical voltage ' $V_{c}$ ' to increase linearly with surface tension. Fig. 8 is a plot of surface critical voltage vs. surface tension of PS.

\subsection{Process parameters}

\subsubsection{Surrounding gas}

The environmental conditions around spinneret such as the surrounding air, the $\mathrm{RH}$, any vacuum conditions and the surrounding gas influence the fiber structure and morphology of the electro- 

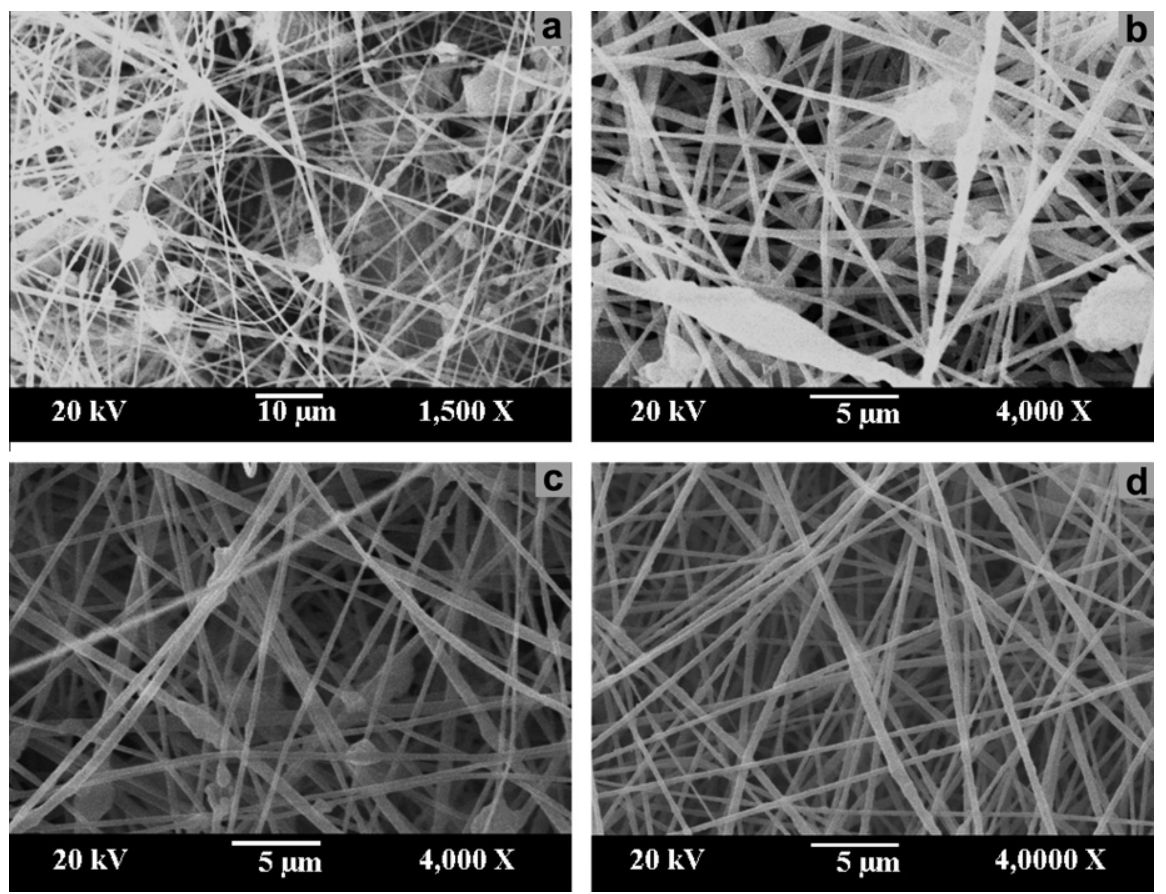

Fig. 6. FE-SEM images of electrospun PAN fibers with different solution concentration (a) 8 wt\% (b) 10 wt\%, (c) 12 wt\%, (d) 14 wt\%.

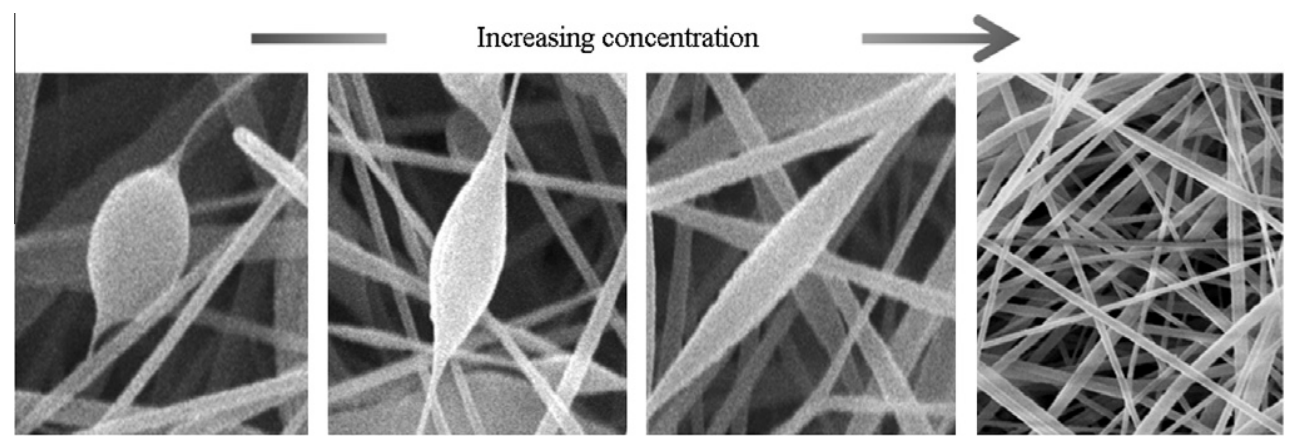

Fig. 7. Effect of solution concentration on bead morphology of electrospun PAN fibers.

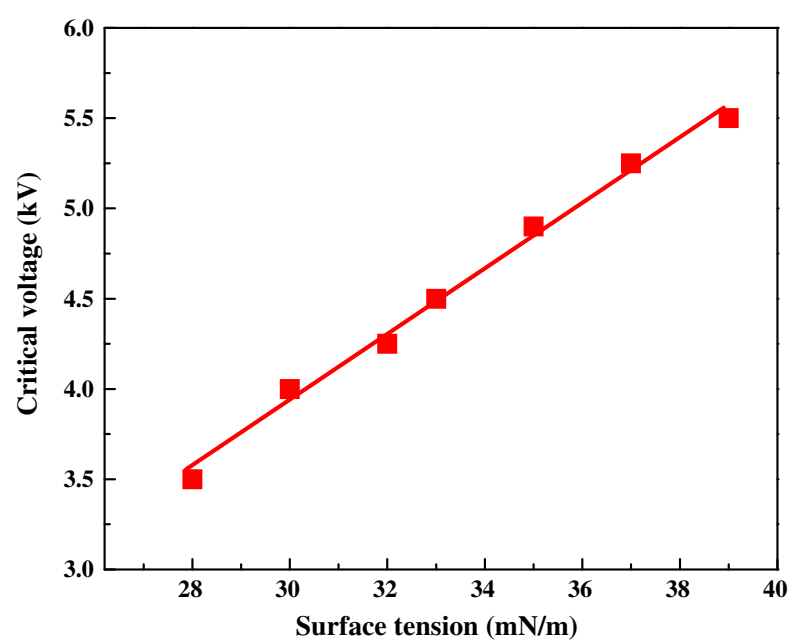

Fig. 8. Plot of critical voltage vs. surface tension for electrospinning of PS in THF/ DMF.

spun membrane. Baumgarten [32] observed that in dry air $(\mathrm{RH}<5 \%)$ spinning drops tended to dry out, spinning being possi- ble for only few minutes. In humid air ( $\mathrm{RH}>60 \%$ ), the fibers do not dry properly and become tangled in the grounded screen. The breakdown voltage of the atmospheric gases influences the charge retaining capacity of the fibers. In helium, no spinning is possible as the gas undergoes electrical breakage at $2500 \mathrm{~V}$. Fibers spun in Freon-12 gas have diameter 1.4-2.6 times greater than those spun in air, possibly due to the higher breakdown voltage of Freon-12 gas than air, which allows fibers to retain electric charges for a long time. Megelski et al. [78] investigated the pore characteristics of polystyrene fibers at varied $\mathrm{RH}$ and evaluated the importance of the phase separation mechanisms in explaining the pre-formation of electrospun fibers.

\subsubsection{Applied voltage}

Various instability modes that occur during the fiber forming process are expected to occur by the combined effect of both the electrostatic field and the material properties of the polymer. Dietzel et al. [75] have suggested that the onset of different modes of instabilities in the electrospinning process depends on the shape of the jet initiating surface and the degree of instability which effectively produces changes in the fiber morphology. In electrospinning, the charge transport due to the applied voltage is mainly due to the flow of the polymer jet towards the collector and the in- 
crease or decrease of current is attributed to the mass flow of the polymer from the spinneret tip. Dietzel reported that the change in spinning current is related to the change in the instability mode [75]. It is reported that an increase in applied voltage causes a change in the shape of the jet initiating point and hence the structure and morphology of the fibers. However there was no significant change observed in the pore size distribution with change in applied voltage [76]. It has been generally accepted that an increase in the applied voltage increases the deposition rate due to higher mass flow from the needle tip. The voltage needed to eject charged jet depends mainly on the solution viscosity. The jet diameter increases in a sigmoidal manner with increasing voltage [42]. Decreasing the electrical field decreases the bead density regardless of the concentration of the polymer solution. Fig. 9 shows the effect of voltage on the bead morphology of PAN. Applied fields can moreover influence the morphology in periodic ways, creating a variety of cross-sections in the fibers. In most cases the electrospun fibers are circular in cross-sections. In addition, electrospinning can produce fibers with a variety of cross-sections. Lace, ribbon, branched or flat ribbon shaped fibers have also been observed $[39,46]$. At high voltage and low viscosity, multiple jets were ejected [75]. For the PEO/water system, Deitzel et al. [75] found the spinning current increases with increasing voltage. The bead structure becomes prevalent at a voltage of about $7 \mathrm{kV}$, coincident with the change in slope in the plot of electrospinning current vs. voltage. Thus they concluded that, by monitoring spinning current, bead defect can be controlled.

Fiber morphology changes with voltage are also related to the original droplet shape. At low voltages, the jet originates from a cone at the bottom of suspending droplet [75]. The fibers produced have a cylindrical morphology with few bead defects. At voltages $>7 \mathrm{kV}$, the cone recedes and the jet originates from the liquid surface within the syringe tip. The fibers produced show a distinct increase in the number of bead defects. At $9.0 \mathrm{kV}$ the jet originates on the inside surface of the syringe needle, where the edge of the liquid surface meets the needle wall. The fibers produced have a high density of bead defects [45].

Lee et al. [45] observed that the bead morphology changes with voltage applied. The aspect ratio increases first and then decreases with increasing voltage, with the transition occurring at $15 \mathrm{kV}$. The increase is due to the increasing repulsion and so higher drawing stress making the bead smaller. No explanation is given for the decreasing trend of aspect ratio. Kim et al. [74] observed in the electrospinning of PAMPSA/ethanol/water mixture that uniform fibers are produced where the viscosity and solution resistivity balance ( $6 \mathrm{wt} \%$ in study) and so the current is at maximum. Raghavan et al. reported the effect of varying applied voltage between 10 and $25 \mathrm{kV}$ on the fiber diameter and morphology of electrospun fibrous membranes with uniform bead free morphology prepared with $16 \%$ PAN solution in DMF [51].

\subsubsection{Feeding rate and tip to collector distance}

The flow rate of the polymer fluid from the syringe is an important process parameter as it influences the jet velocity and the material transfer rate. Fong et al. [79], for electrospinning of PDLA, observed that a minimum solution volume at the end of the spinneret should be present for the equilibrium Taylor cone to form. With a lower solution feeding rate, smaller the fibers with spindle-like beads are formed and vice versa. Mangelski et al. [78] reported that the fiber diameter and the pore diameter increased with an increase in the polymer flow rate. As the flow rate increased, the fibers had pronounced beaded morphologies and the mean pore-size increased from 90 to $150 \mathrm{~nm}$. TCD has certain influence on fiber morphology, but it is less significant. With increasing TCD, the electrostatic force decreases and so the drawing stress decreases. This leads to a decrease in the aspect ratio and an increase in the size of beads, although it facilitates deposition of more solidified or dried fibers on the collector. Fig. 10 shows the effect of tip to collector distance on the bead morphology in electrospinning of PAN.

\section{Fibers with engineered morphology}

Deitzel et al. [80] proved the feasibility of obtaining fibers with specific surface chemistry. Ma et al. [73] modified the surface of non-woven PET fiber mats to be biocompatible for endothelial cells by treating fibers with formaldehyde followed by the grafting polymerization of MAA initiated by Ce (IV). The fibers were then further grafted with gelatin, which improved the proliferation of the endothelial cells preserving their phenotype. Kim et al. [72] fabricated low cost, high-purity carbon sheets with fibers having average fiber diameter of $250 \mathrm{~nm}$ from PBI by electrospinning and subsequent heat treatment up to $300^{\circ} \mathrm{C}$. High crystallinity (up to $30 \%$ ) was achieved giving increased electrical conductivity and specific gravity. Park et al. [81] separated a DMF soluble fraction from an isotropic pitch precursor and electrospun remaining part in THF to get carbonized fibers. Fibers have a dumb-bell like cross-section due to incomplete splitting. The electrical conductivity of fibers is 10 times higher than carbonized fibers from polymers like PAN, PI, etc. making them suitable for use as electrodes. Wang et al. [82] electrospun field responsive superparamagnetic polymeric fibers from colloidallystable suspensions of magnetite nanoparticles in PEO and PVA solutions. The magnetite nanoparticles were aligned parallel to the fiber axis within the fiber; the composite fibers exhibited superparamagnetic behavior at room temperature.

Yang et al. [64] made conductive PAN fibers by introducing Ag nanoparticles during electrospinning. The conductivity of the fiber was as high as $10^{-7} \mathrm{~S} / \mathrm{cm}$ against $10^{-14} \mathrm{~S} / \mathrm{cm}$ for pure PAN fiber. Kim et al. [83] electrospun poly(amic acid) solution, imidized and finally carbonized in temperature range from 700 to $1000^{\circ} \mathrm{C}$ in

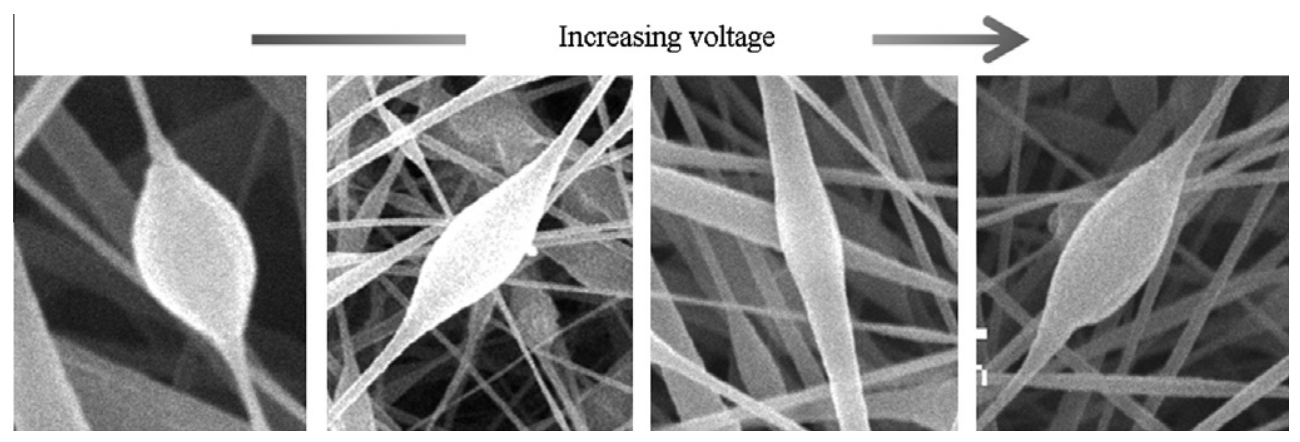

Fig. 9. Effect of applied voltage on bead morphology of electrospun PAN fibers. 


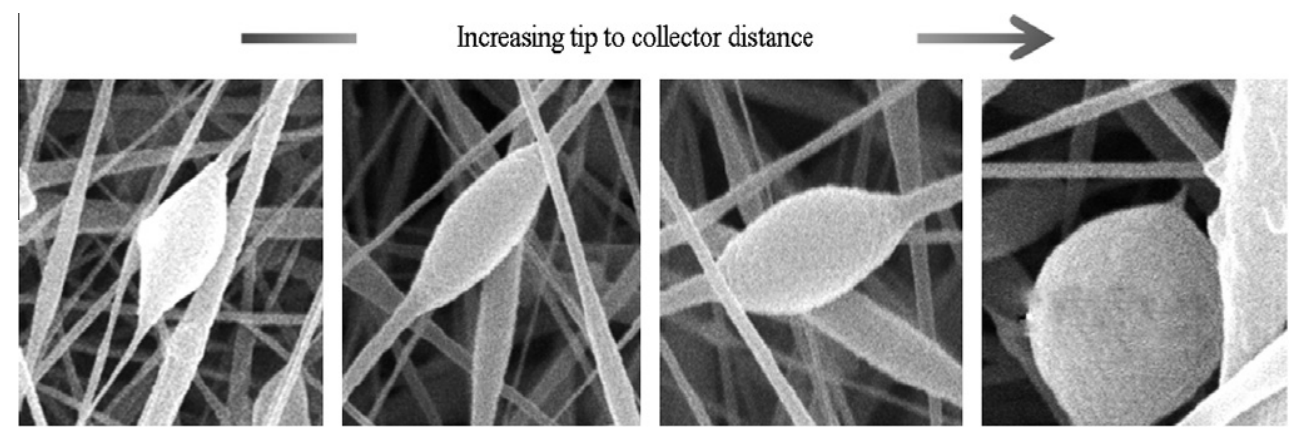

Fig. 10. Effect of tip to collector distance on bead morphology of electrospun PAN fibers.

nitrogen. The carbonized fiber web has a relatively high electrical conductivity of $2.5 \mathrm{~S} / \mathrm{cm}$. When tested electrochemically for the performances as electrodes of EDLCs, it gave good performance with specific capacitance of $175 \mathrm{~F} / \mathrm{g}$ even at a high current density of $1000 \mathrm{~mA} / \mathrm{g}$. Choi et al. [58] studied the application of thermally treated electrospun PVDF fiber webs as an electrolyte binder or as a separator for a battery. The web was treated with ethylene plasma to introduce a polyethylene layer on the mat surface to use the mat as a separator with a shutter.

While most fibers are produced as a non-woven material, only continuous single fibers or uniaxial fiber bundles can provide optimum applications. However this is very difficult to achieve; the polymer jet trajectory is a very complicated 3D "whipping" caused by bending instability. Several approaches have tried to align electrospun fibers. Li et al. [84] reported a simple and versatile method for obtaining aligned fibers of PVP and ceramic materials by replacing the grounded electrode with a collector consisting of two pieces of conductive silicon strips separated by a void gap varied from hundreds of micrometers to several centimeters.

Li et al. [85] made electrospun fibers with a core/sheath or hollow structure. The surface area of a fiber can be greatly increased when its structure is switched from a solid to a porous one. Wendorff and coworkers reported PLA/PVP blend fibers with a highly porous structure [86]. The same group also found that porous fibers of PLLA and polycarbonate could be directly obtained by the judiciously selected the spinning parameters and the solvent system [87]. Megelski et al. [78] and Casper et al. [63] have observed that solvent vapor pressure and humidity in the spinning chamber strongly affect the formation of pores on the fibers. Li et al. [85] demonstrated that porous ceramic fibers could be fabricated by electrospinning with the use of a coaxial double capillary system. Wang and co-workers [88] successfully prepared continuous polymer fiber yarns by self-bundling electrospinning. They reported self-bundled continuous yarns of PHBV, PAN, PLLA and PMIA.

Electrospun fibers show superior properties such as high surface area and aspect ratios, low density, high porosity, and exceptional mechanical strength [18]. During the last two decades, electrospinning has received much attention by the scientific community and the process has been extended to the preparation of hybrid [89-92] and inorganic [93,94] onedimensional nanomaterials. By the optimization of solution and processing parameters $[95,96]$ and/or modification of electrospinning set-up [97] this mature technology has been extended to prepare complex nanostructures such as non-woven, aligned or patterned fibers, nanowires, nanoribbons, nanorods, random three dimensional structures, porous fibers and convoluted fibers with tuned properties and controlled diameters $[98,99]$. By specially designed and fabricated spinnerets, fibers with hierarchical properties and structures such as core-sheath [100], hollow fibers and spheres [85], multichannel microtubes $[101,102]$ and porous fibers [103] were prepared and the process is termed as core-shell or co-electrospinning. Also co-electrospinning was elaborated to prepare the fibers with multi phase fibers and membranes with interlaid fibrous network of different materials [104].

Solution electrospinning is widely used for preparing nanofibers. In most cases the solution is prepared in organic solvents, which can cause environmental issues. Solvents for dissolving polymers may be remnants on the fiber, leading post-spinning process such as drying, washing or chemical treatments. Also most of the solvents are costly, and it will make the process expensive. Due to the contamination of materials by the solvent, solution based electrospun fibers are not scientifically compatible and are not preferable to use in medical and biological applications like wound dressing or mechanical support for tissue reconstructions. Therefore, in spite of the many potential applications, due to the environmental and health limitations as well as process complications and economic aspects, there is a persistent desire to use alternative methods to prepare nanofibers. Also there is a lack of solvent system to dissolve a vast variety of polymers, which will restrict the spinning of the polymers such as polyethylene and polypropylene [105]. Melt electrospinning is an alternative approach to overcome technical and environmental restriction in solvent based electrospinning. In melt electrospinning, the polymer melt is fed to the capillary connected to high voltage source.

\section{Studies towards potential applications}

Electrospun fibers show superior properties such as high surface area and aspect ratios, low density, high porosity, and exceptional mechanical strength [18]. Initially the method was used for preparing high performance polymer membranes [38]. Recently electrospun fibers find a vast area of applications. The applications of electrospinning fibers are broadly classified as filtration, protective clothing, biomedical applications, tissue engineering scaffolds, structural applications requiring high mechanical strength, release control, catalyst and enzyme carriers, energy storage, sensors, wound healing, space applications, reinforcement for composite materials, micro and nano-optoelectronics, etc. Fig. 11 shows the relative proportion of literature in the advanced applications of electrospun fibers. The feasibility of electrospinning piezoelectric polymers was studied for applications in sophisticated aerospace fields such as the MAV (Micro-Air Vehicle) normally used for collecting and transmitting visual images from hazardous locations; Pawlowski et al. [106] had electrospun ( $\beta-C N$ ) APB-ODPA and PVDF from solutions in DMAc and DMF respectively with efforts to get aligned fibers. They also electrospun the piezoelectric copolymer of PVDF and TrFE [71] as it has higher crystallinity than PVDF alone and it is not necessary to stretch the copolymer to induce a polar crystalline phase.

While the electrospinning process itself is over 70 years old, the concept of electrospun scaffolding for biomedical applications ap- 


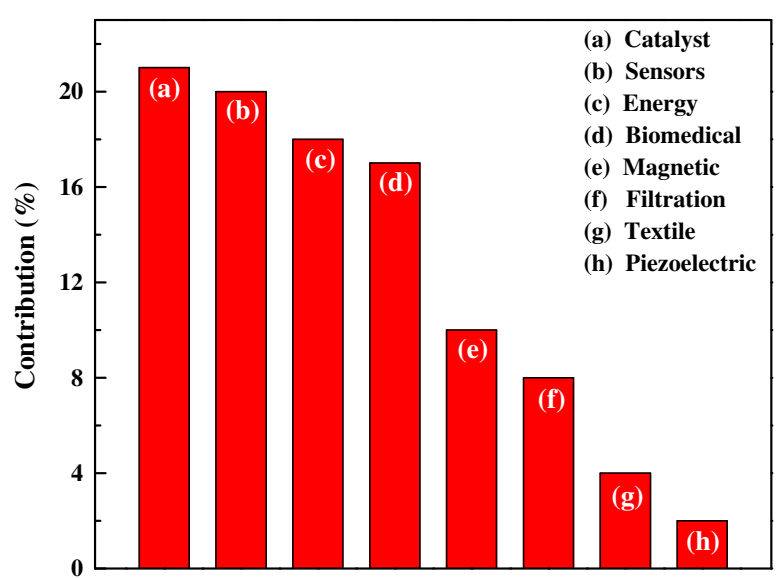

Fig. 11. Statistics on the literature published on the advanced applications of electrospun fibers in the period 2001-2012 (search made through Scifinder: Keywords Electrospinning + area of application).

pears to have first emerged in 1978. An elastomeric vascular prosthesis was reportedly produced from a PU elastomer utilizing electrospinning by Annies et al. [107]. Kahol et al. [108] showed that electrospun fibers of camphorsulfonic acid doped PANCSA blended with PEO ((PANCSA) $\left.{ }_{0.72}(\text { PEO })_{0.28}\right)$ exhibit increased Pauli susceptibility, a narrower EPR line and increased Lorentzian behavior than corresponding cast films. They interpreted these as a result of increased chain alignment in the fibers. Chen et al. [109] electrospun poly(ferrocenylsilane) with alternating ferrocene and silicon atoms, having novel redox, electrical, optical and chemical properties. They could successfully characterize the crystal structure of the electrospun fibers as monoclinic.

Huang et al. [110] electrospun genetically modified elastinmematic protein with the sequence (Val-Pro-Gly-Val-Gly) ${ }_{4}$ (ValPro-Gly-Lys-Gly) in distilled ultrafiltered water. They claimed it to be important in characterizing those physiochemical and biological properties required for engineering improved human tissue constructs. Kenawy et al. [57] electrospun poly(ethylene-co-vinyl alcohol) to produce biodegradable porous material for wound covering and healing. They even could directly spin a mat onto living tissue (human hand). Ding et al. [111] prepared biodegradable fibrous mats comprising PVA and CA via multi-jet electrospinning having very good dispersibility.

Kenawy et al. [67] also explored the use of electrospun fiber mats of PLAA, PEVA and their blend as drug delivery vehicles. Electrospun PEVA and 50/50 PLAA/PEVA mats gave relatively smooth release of drug over about 5 days; but they did not investigate why 50/50 PLAA/PEVA film showed a substantial 25\% release in about $120 \mathrm{~h}$. Zeng et al. [112] could capsulate drugs inside electrospun PLLA fibers. Drug release in the presence of proteinase $\mathrm{K}$ followed nearly zero-order kinetics due to the degradation of the fibers. Yoshimoto et al. [113] electrospun porous, non-woven PCL scaffolds and cultured, expanded and seeded mesenchymal stem cells derived from the bone marrow of rats on these. Cell-polymer constructs were covered with cell multilayers at 4 weeks along with mineralization and type I collagen; proving electrospun PCL to be potential candidate scaffold for bone tissue engineering.

Selection of suitable chemical compositions in electrospinning may be useful in production of new biodegradable scaffolds suitable for different biomedical applications as well as prevention of postsurgical adhesion. Kim et al. [114] studied PLA-based scaffolds to alter such properties electrospinning their blends with miscible PLGA random copolymers, PLA-b-PEG-b-PLA triblock copolymers, etc. with hydrophobicity decreased by $\sim 50 \%$. The first demonstration of plasmid DNA incorporation into a polymer scaffold using electrospinning was given by Luu et al. [115] through the use of composite scaffolds from PLGA random copolymer and a PDLLAPEG block copolymer. Zong et al. [116] studied the microstructure, morphology and texture of electrospun poly(glycolide-co-lactide) (GA:LA, 90:10) membranes after post-drawing and thermal treatments to tailor the degradation and mechanical properties The membranes exhibited a slower degradation rate than as-spun membranes initially, increasing after 2 weeks. Sawicka et al. [117] electrospun biocomposite fibers from urease for urea biosensing. This acts as a very efficient enzyme for the hydrolysis of ammonia and $\mathrm{CO}_{2}$ and PVP.

Huang et al. [60] studied the electrospinning of gelatin and the concentration-mechanical property relationship of the resulting fiberous membranes. Gelatin/water solution was not electrospinnable; so TFE was used. Zhang et al. [66] studied the production of core-shell structured PCL-r-gelatin bi-component fibers by coaxial electrospinning. Core-shell nanostructures have a potential in preserving unstable biological agents, preventing decomposition of labile compounds, and delivering biomolecular drugs in a sustained way. Gibson et al. [118] studied the transport properties of electrospun fiber mats. They found that they have quite large resistance to convective gas flow, comparable to PTFE membrane. They can exclude aerosol particles also. Ding et al. [65] fabricated a novel gas sensor and a QCM from electrospun fibrous membranes of blend of PAA and PVA. The sensitivity of the QCM sensor coated with the fibrous membrane was claimed to be much higher than that coated with a continuous film.

For filtration application, polymer fibers can be electrostatically charged to enhance attraction towards particles without any increase in pressure drop. Tsai et al. [119] discussed the advantage of using electrospinning in integrating both spinning and charging in a single step. Madhugiri et al. [120] has electrospun a non-woven mesh of porous molecular sieve fibers; which can be used in smart textiles, catalysis, etc. Fong et al. [121] studied the quite unexplored field of fabricating and processing nanoscale structures from dissolved polymer nanocomposites. They achieved highly aligned montmorillonite layers and nylon crystallites by electrospinning of exfoliated montmorillonite clay-nylon nanocomposites. This may enable alternative approaches to coating, film and fiber fabrication.

\section{Energy conversion and storage}

In most batteries a porous structure is an essential requirement for PEs. PE may be generally defined as a membrane that possesses transport properties comparable with that of common liquid electrolytes. PEs have received considerable attention in recent years for application in rechargeable secondary batteries, fuel cells, and supercapacitors since they can offer systems that are lighter, safer and more flexible in shape compared with their liquid counterparts $[1,2]$. The impact of electrospun fibers in lithium ion battery in terms of number of publications per year is illustrated in Fig. 12. This review also highlights the potential applications and recent advances of electrospun fibrous materials for lithium ion batteries. In principle, a polymer electrolyte battery can be formed by sandwiching the electrolyte between a lithium metal anode (or a composite carbon) and a composite cathode as depicted in Fig. 13. The charge discharge profile of the lithium battery is presented in Fig. 14. The electrospinning is capable to prepare novel materials with enhanced electrochemical properties of the primary functional components (electrolyte, anode and cathode) of lithium ion batteries.

\subsection{Polymer electrolytes}

The prerequisites for a polymer electrolyte for lithium batteries are high ionic conductivity at ambient and sub-ambient tempera- 


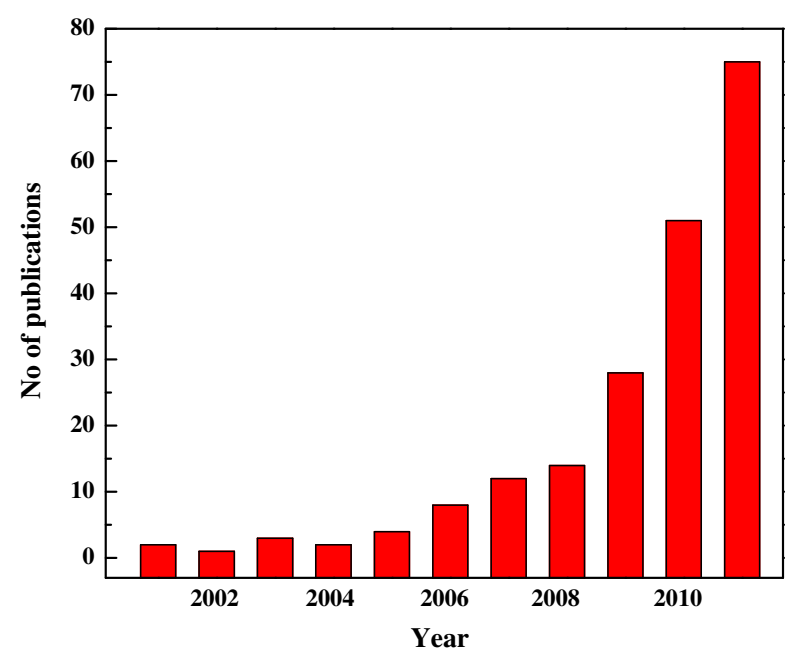

Fig. 12. Number of research articles published on electrospun fiber application in lithium ion batteries published in the period of 2001-2011 (Scifinder data: Keywords electrospinning + Li-ion batteries).

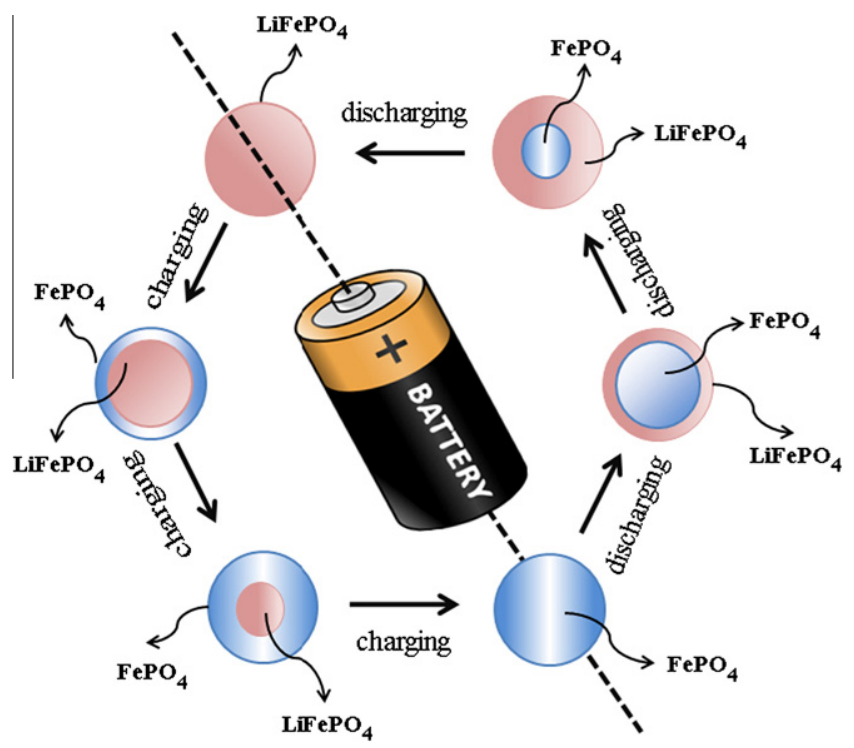

Fig. 13. Principle of $\mathrm{LiFePO}_{4}$ charge/discharge process in lithium ion battery.

tures, good mechanical strength, appreciable ion transference number, thermal, electrical and chemical stabilities and good compatibility with the electrodes [122]. PEs should allow good cycle life and must withstand the internal pressure built up during battery operations [123-135]. Although PEs were launched in 1973 by Fenton et al. [128] and their technological importance boomed up to 1980 [129], the development of PEs has gone through three materials stages; dry solid state polymers, gel/plasticized polymer electrolytes and polymer composites. The host of polymers reported for the preparation of polymer electrolytes include PVDF [130-132] and its copolymer P(VdF-HFP) [1-5,122], PEG [133], poly(urethane acrylate) [134], PAN [134], PMMA [136], and PEO [137].

The ionic conductivity and electrochemical properties of the PEs depend not only on the polymer host, but also the host polymer membrane properties such as pore size, porosity and pore distribution, which are strongly dependent on the membrane processing method. Different methods such as solvent casting [138], plasticizer extraction [139,140] and phase inversion [141-144] have
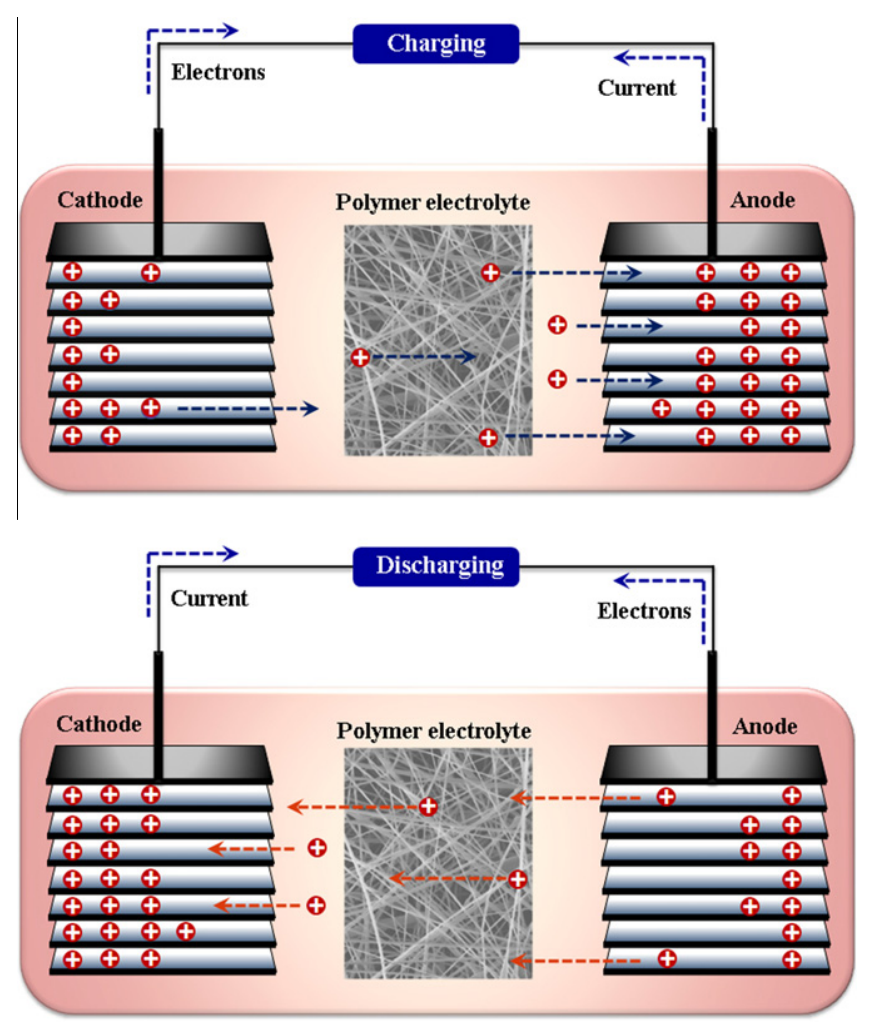

Fig. 14. Schematic representation of charging and discharging processes of lithium ion battery with PE based on ESM.

been adopted for preparing such porous membranes. In 1996, a liquid extraction/activation method was developed by Bellcore to prepare porous $\mathrm{P}(\mathrm{VdF}-\mathrm{HFP})$ film separators. The membranes prepared by plasticizer extraction possess good ionic conductivity and electrochemical stability. Unfortunately their capabilities at high-discharge rates are limited due to the nano-scale pore size and low porosity ( $\sim 50 \%)$ of the matrix. It is not easy to extract all the plasticizer and leave the same volume of pores in the film by extraction. Also it is difficult to absorb sufficient amount of electrolyte in the activation step. Moreover, the extraction step causes more complication during large scale production. In order to improve the membrane properties the phase inversion method $[145,146]$ was introduced to prepare a porous film of $\mathrm{P}(\mathrm{VdF}-$ HFP). With the phase inversion method porous membranes (pore size: $0.1-1 \mu \mathrm{m}$ ) with porosity $>70 \%$ can generally be obtained and these membranes can absorb larger amounts of electrolyte solution. Increasing the pore size in the matrix from nano to micro-scale can help to enhance both the mobility of ions and the ionic conductivity [147].

Recently, electrospinning has attracted immense attention as an alternative, simple and efficient method to prepare polymer membranes with fully interconnected pore structure [1,3]. Interest in this mature technology was revived in the 1980s when it was demonstrated that the process could be used to fabricate ultrafine fiber and fibrous membranes of various polymers with fiber diameters down to submicrons to nanometers. These fibrous polymer membranes have high porosity and an interconnected open pore structure, so the electrolyte solution can be easily encapsulated within the matrix. As a result, this structure can contribute to a high ionic conductivity, and with sufficient mechanical strength, may be more suitable for lithium-ion battery fabrication. With proper control of the process parameters, fibrous membranes with porosities of $30-90 \%$ and pore size in the range of submicron to few microns can be made. The ESM appears to be suitable for use as host matrix 
in porous PEs because of the fully interconnected pores with large surface area facilitating high electrolyte uptake and easy transport of ions. Moreover, the resulting PEs show lower bulk impedance (Fig. 15) and higher rate capability [148]. Polymer electrolytes based on ESMs show good mechanical strength [1]. Fig. 16 shows the SEM image of electrospun PAN after soaking for $24 \mathrm{~h}$ in liquid electrolyte.

Polymer electrolytes based on electrospun PVDF [58,149-153] and its copolymer P(VdF-HFP) [1-5,122,154-156] has been widely investigated for lithium battery applications. The PVDF fiberous membranes shows high electrolyte uptake (>400\%), [149] high ionic conductivity $\left(1.7 \times 10^{-3} \mathrm{~S} \mathrm{~cm}^{-1}\right.$ at $\left.0^{\circ} \mathrm{C}\right)[128]$ and high anodic stability of more than $5 \mathrm{~V}$. Choi et al. [149] showed that the electrolyte uptake of the electrospun membrane depends on the solvent or the ratio of solvent components in the solvent mixture used for the preparing polymer solution. They found that the performance of elecrospun PVDF membranes depended largely on the physical properties of the fibers. Decrease in AFD leads to an increase in electrolyte solution uptake due to the decrease in pore size and increase in specific surface area. It is generally known that membranes with small pore size and high specific surface area have great ability to absorb electrolyte solution. Table 3 shows the electrolyte uptake of PVDF membranes with different AFD. On contrary, Choi et al. [149] reported electrospun PVDF membranes prepared using acetone and/or acetone/DMAc (9:1 wt/wt) which consisted mainly of thick fibers but showed large electrolyte uptake. This indicates that electrolyte uptake depends not only on the average fiber diameter of the electrospun fibers but also on the morphology of the membrane. The cell fabricated with PEs based on PVDF electrospun membranes exhibited high charge discharge properties and very stable cycle performance $[149,151,152]$. However, electrospun fibrous membranes have inferior physical properties due to the non-woven state. Choi et al. [58] reported that the physical properties and dimensional stability of the electrospun PVDF membranes can be improved by thermal treatment and a thin layer of polyethylene was plasma polymerized onto the fiber surface. In the latter the PVDF mat acted as a separator with a role of the shutter by melting of the polyethylene layer grafted, which improved the safety of the battery. It was found that modulus, tensile strength and elongation at break of the thermally treated mat were considerably improved after thermal treatment. The improved physical properties may be due to the increased crystallinity, mat shrinkage and fiber thickening. The AFD significantly affected the physical properties of the fibrous membranes

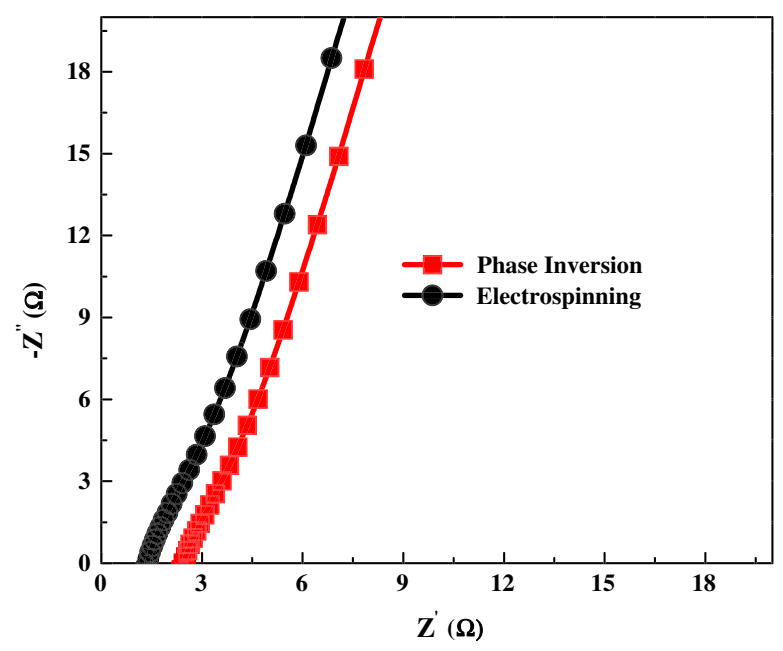

Fig. 15. Bulk resistance of PEs based on $\mathrm{P}(\mathrm{VdF}-\mathrm{HFP}) \mathrm{ESM}$ and phase inversion membranes.

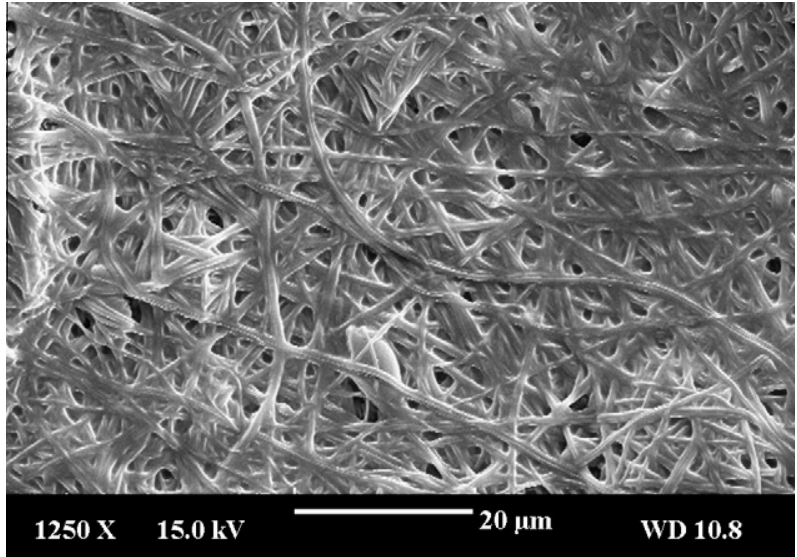

Fig. 16. FE-SEM image of electrospun PAN membrane after $24 \mathrm{~h}$ soaking in the liquid electrolyte $1 \mathrm{M} \mathrm{LiPF}_{6}$ in EC/DMC $(1: 1 \mathrm{v} / \mathrm{v})$.

such as porosity, pore size, pore size distribution and specific surface area and tensile strength. Kim et al. [151] reported that, when the AFD is increased from 1.1 to $4.3 \mu \mathrm{m}$, its apparent porosity decreased from $89 \%$ to $80 \%$.

There are lots of reports on the P(VdF-HFP) based fibrous PEs with enhanced electrochemical and physical properties [15,122,154-156]. Kim et al. [155] reported a power law relationship with an exponent of about 4.1 between solution concentration and the AFD of P(VdF-HFP) based electrospun fibrous membranes. When the polymer concentration increased the overall distribution of fiber diameter became broader. It was found that the porosity and electrolyte uptake of PEs based on P(VdF-HFP) decreases with increase in solution concentration. Li et al. [3] also reported the same observations. The ionic conductivity and anodic stability was higher than PVdF based membranes. This is due to the lower crystallinity of the $\mathrm{P}(\mathrm{VdF}-\mathrm{HFP})$. PEs based on $\mathrm{P}(\mathrm{VdF}-\mathrm{HFP})$ exhibit excellent charge discharge and cycle performance. Kim et al. [156] reported excellent cycle performance of a PE based on $\mathrm{P}(\mathrm{VdF}-\mathrm{HFP})$ fibrous membrane with PTMA based cathode materials. Even at higher $\mathrm{C}$-rate $\left(30^{\circ} \mathrm{C}\right)$ the cells show excellent cycle performance of up to 100 cycles. $\mathrm{P}(\mathrm{VdF}-\mathrm{HFP})$ based fibrous PEs incorporating room temperature ionic liquids have also been reported [4,5,122]. An ionic conductivity of $2.3 \times 10^{-3} \mathrm{~S} \mathrm{~cm}^{-1}$ and an anodic stability of about $5.5 \mathrm{~V}$ were achieved with the electrolyte LiTFSI in BMITFSI, and it showed excellent cycle performance. Kim et al. [5] made $\mathrm{P}(\mathrm{VdF}-\mathrm{HFP}) / \mathrm{SiO}_{2}$ composite membranes by electrospinning. The composite membranes showed higher ionic conductivities than the membranes without $\mathrm{SiO}_{2}$ having the same porosity. It is reported that the incorporation of $\mathrm{SiO}_{2}$ results in thicker fibers and less homogenous fibers due to the increase of solution viscosity. Raghavan et al. further improved the ionic conductivity and electrochemical properties of $\mathrm{P}(\mathrm{VdF}-\mathrm{HFP})$ based electrospun PEs by incorporating nano-sized ceramic fillers $\left(\mathrm{SiO}_{2}\right.$, $\left.\mathrm{Al}_{2} \mathrm{O}_{3}, \mathrm{BaTiO}_{3}\right)[1,2,122]$. However, mechanically mixed $\mathrm{SiO}_{2}$ particles can aggregate and the nanoparticles cannot be uniformly distributed in the polymer matrix. In order to overcome this problem, Raghaven et al. prepared $\mathrm{P}(\mathrm{VdF}-\mathrm{HFP}) /$ in situ generated $\mathrm{SiO}_{2}$ composite fibers by electrospinning [1]. Comapred to mechanically mixed $\mathrm{SiO}_{2}$ nanoparticles, the incorporation of $6 \%$ in situ generated $\mathrm{SiO}_{2}$ improved the ionic conductivity from $4.59 \times 10^{-3}$ to $8.06 \times 10^{-3} \mathrm{~S} \mathrm{~cm}^{-1}$. In addition to PVDF based copolymer, organomodified clay (OC)/tripropyleneglycol diacrylate (TPGDA) modified PVDF also showed improved mechanical properties because of the chemical crosslink [157]. The improvement of the handling strength and ionic conductivity of polymer electrolytes has also been well illustrated $[158,159]$. 
Table 3

AFD, electrolyte uptake and electrochemical properties of polymer electrolytes based on electrospun PVDF membranes.

\begin{tabular}{|c|c|c|c|c|c|c|}
\hline Solvent & AFD $(n m)$ & Electrolyte & Uptake (\%) & $\sigma(\mathrm{S} / \mathrm{cm})$ & LSV (V) & Ref. \\
\hline DMAC & $400-500$ & $1 \mathrm{M} \mathrm{LiN}\left(\mathrm{CF}_{3} \mathrm{SO}_{2}\right)_{2}$ in water & $50-73$ & $1.6-2 \times 10^{-3}$ & & {$[58]$} \\
\hline Acetone/DMAc (3:7) & 250 & $1 \mathrm{M} \mathrm{LiPF}_{6}$ in EC/DMC $(1: 1 \mathrm{wt} / \mathrm{wt})$ & 260 & $1.7 \times 10^{-3}$ at $0{ }^{\circ} \mathrm{C}$ & 4.5 & {$[150]$} \\
\hline Acetone/DMAc ( $7: 3)$ & 450 & $1 \mathrm{M} \mathrm{LiPF}_{6}$ in EC/DMC/DEC $(1: 1: 1 \mathrm{wt} / \mathrm{wt} / \mathrm{wt})$ & 340 & $9.1 \times 10^{-3}$ & 5.0 & {$[151]$} \\
\hline Acetone/DMAc $(7: 3)$ & 300 & $1 \mathrm{M} \mathrm{LiPF}_{6}$ in EC/DMC/DEC (1:1:1 wt/wt/wt) & 344 & $1.04 \times 10^{-3}$ at $20^{\circ} \mathrm{C}$ & 4.7 & {$[152]$} \\
\hline
\end{tabular}

The AFD of the membranes increases with increase of silica content and the effect is more pronounced in the case of directly added nano-silica. The AFD of a membrane with $6 \%$ in situ generated silica was $1.2 \mu \mathrm{m}$ and that of directly added silica $0.7 \mu \mathrm{m}$ higher. The ionic conductivity increased to a maximum with silica content and then decreased. The electrolyte uptake was increased from $425 \%$ to $592 \%$ by the addition of $6 \%$ silica, and the tensile strength was improved from 6.5 to $10.9 \mathrm{MPa}$. A comparison of P(VdF-HFP) electrospun membranes comprising $6 \mathrm{wt} \%$ of different ceramic fillers was also reported with $1 \mathrm{M} \mathrm{LiPF}_{6}$ in EC/DMC and $1 \mathrm{M}$ LiTFSI in BMITFSI $[2,122]$. By the addition of the ceramic filler, the crystallinity of the fibrous membrane decreased and both the ionic conductivity and the electrochemical properties were improved. A PE comprised of $6 \mathrm{wt} \% \mathrm{BaTiO}_{3}$ and in situ generated silica evaluated using a carbon coated $\mathrm{LiFePO}_{4}$ cathode delivered a discharge capacity of $170 \mathrm{mAh} \mathrm{g}^{-1}$ which corresponds to the $100 \%$ utilization of active material. It also showed a stable cycle performance. The same result was also observed with RTIL [122].

Fibrous membranes from other classes of polymers such as PAN were also studied as PEs for lithium batteries [160,161]. The electrospun membrane shows high ionic conductivity high thermal stability, good compatibility with electrolytes and electrode and good electrochemical properties. A porous PAN non-woven membrane was electrospun by Cho et al. $[161,162]$. The PAN membranes showed higher ionic conductivities, higher capacity retention and better rate capabilities. Ju et al. [163] electrospun polypyrrole (PPy)/sulfonated-poly(styrene-ethylene-butylenestyrene) (SEBS) fibers with the addition of sulfonated SEBS. This resulted in an improvement in the electrical conductivity of the composite fibers, and thus the electrochemical capacity was increased. A prototype cell based on an electrospun PAN membrane with $1 \mathrm{M}$ $\mathrm{LiPF}_{6}$ in $\mathrm{EC} / \mathrm{DMC}$ with a $\mathrm{LiCoO}_{2}$ cathode was reported to exhibit an initial discharge capacity of $145 \mathrm{mAh} \mathrm{g}^{-1}$ and $91.4 \%$ of the initial discharge capacity after 150 cycles at a charge/discharge rate of $0.5 \mathrm{C}$ [160]. Cho et al. [161] also reported a discharge capacity of $\sim 125 \mathrm{mAh} \mathrm{g}^{-1}$ with $\mathrm{LiCoO}_{2}$ and $1 \mathrm{M} \mathrm{LiPF}_{6}$ in $1 \mathrm{M} \mathrm{EC} / \mathrm{DEC}$, and $85 \%$ of initial discharge capacity was retained after 200 cycles. Jung et al. [53] investigated the effect of silica on the morphology and electrochemical properties of the electrospun PAN with varying concentration of silica from 0 to $15 \mathrm{wt} \%$. It is generally accepted that the AFD increases with solution viscosity. By the addition of silica the viscosity of the polymer solution increases exponentially with silica content and it forms fibers with higher AFD. On the contrary, Jung et al. [53] reported that the AFD of the membranes decreases with increase of silica content. The PEs exhibited good ionic conductivity $\left(1.2 \times 10^{-3} \mathrm{~S} \mathrm{~cm}^{-1}\right)$, anodic stability, cycle performance and excellent interfacial resistance $(75 \Omega)$. The ionic conductivity increased with increased silica content up to $12 \mathrm{wt} \%$ $\left(1.1 \times 10^{-2} \mathrm{~S} \mathrm{~cm}^{-1}\right)$ and then decreased. The effect of spinning parameters on the morphology of the PAN based electrospun membranes and incorporation of $\mathrm{SiO}_{2}$ and nano-clay were also reported [53]. Recently high molecular weight PAN based electrospun membrane with an ionic conductivity of $1.7 \times 10^{-5} \mathrm{~S} \mathrm{~cm}^{-1}$ was reported [52].

Gopalan et al. [19] investigated the electrochemical properties of PEs based on electrospun PVDF-PAN blend. It was found that the AFD of the fibers increased with PAN content from 250 to
$400 \mathrm{~nm}$ and the electrolyte uptake decreased with increase of PAN from 25 to $75 \mathrm{wt} \%$. A pouch cell fabricated with $1 \mathrm{M} \mathrm{LiClO}_{4}$ in $\mathrm{PC}$ and $\mathrm{LiCoO}_{2}$ cathode exhibited good charge-discharge properties and the decrease in capacity was at a rate of $0.05-0.09 \%$ per cycle with increasing PAN content. To exploit the advantageous properties of both PAN and $\mathrm{P}(\mathrm{VdF}-\mathrm{HFP})$ a trilayer membrane of $\mathrm{P}(\mathrm{VdF}-\mathrm{HFP})$ and PAN was fabricated through continuous electrospinning with the different polymer solutions ( $\mathrm{P}(\mathrm{VdF}-\mathrm{HFP})$ layer sandwiched between two PAN layers and vice versa). The multilayered composite did not perform as well as a membrane electrospun from a solution-based blend of the two polymers, indicating that there are more beneficial interactions between them when electrospun from the same solution, resulting in greater porosity and electrolyte uptake despite larger AFD [104]. Tri-polymer blend of PANPS-PMMA with improved ionic conductivity and electrochemical properties also has been reported [164].

\subsection{Anode materials}

Besides being used as a separator, electrospun fibrous membranes could also be used as battery electrodes [165-168]. Electrospun electrode materials show high specific energy and energy/ charge density, high reversibility, high rate capability to $\mathrm{Li}^{+}$intercalation and deintercalation and cycleability for enhancing the power density. The large surface area of the nanoparticles makes higher electrode/electrolyte contact area to enhance the battery performance and life of the battery. Recently extensive studies were reported on the high performance of nanostructured electrodes in lithium ion batteries $[169,170]$. Cycle life, discharge capacity and power density of the battery greatly depend on the amount of $\mathrm{Li}^{+}$which can be stored in the anode during charging and how easily the intercalated $\mathrm{Li}^{+}$can be moved back to the cathode when the battery is discharged.

The most popular and widely used commercial anode material in lithium-ion batteries is carbon. As an anode material carbon is an environmentally friendly and low cost material with good cycle life. However, the theoretical capacity $\left(372 \mathrm{mAh} \mathrm{g}^{-1}\right)$ and rate capability of graphite are poor [171]. Carbonized PAN fiber at $1000{ }^{\circ} \mathrm{C}$ was used as anode in a lithium ion secondary battery, and the battery showed a good reversible capacity of $450 \mathrm{mAh} \mathrm{g}^{-1}$, which is higher than $372 \mathrm{mAh} \mathrm{g}^{-1}$, the theoretical capacity for graphite [165]. There are many researchers devoted to improve the electrochemical properties of carbon anode and improve the rate capability in lithium ion batteries $[168,172] \mathrm{Ji}$ et al. [173175] have synthesized porous carbon nanofibers (CNFs) using electrospinning. This material shows initial reversible capacities of about $566 \mathrm{mAh} \mathrm{g}^{-1}$ and $435 \mathrm{mAh} \mathrm{g}^{-1}$ after 50 cycles. This result can be ascribed to the high porosity, high surface area and good electrical conductivity developed by the CNFs. Among the anode materials reported, silicon has the highest theoretical capacity at $3572 \mathrm{mAh} \mathrm{g}^{-1}$ [176]. Unfortunately the silicon anode shows very poor cycling stability. The cycle performance of silicon anode was enhanced by preparing composite carbon anode with silicon nanoparticles [177,178]. Electrospun carbon fibers with transition metal oxides also have higher theoretical capacity. However, transition metal oxides suffer from poor cycling performance [179]. It was demonstrated that the performance of transition metal oxides 
was improved by doping CNF with nano-sized transition metal oxide nanoparticles such as $\mathrm{Sn}$ [180-183], $\mathrm{Co}_{3} \mathrm{O}_{4}$ [184], $\mathrm{Fe}_{3} \mathrm{O}_{4}$ [185] and $\mathrm{MnO}_{\mathrm{x}}$ [186]. Sn has high theoretical capacity of $992 \mathrm{mAh} \mathrm{g}^{-1}$, but its cycle performance is poor. The rate capability and cycle performance were improved greatly by dispersing Sn nanoparticles within CNF which will prevent the aggregation of the nanoparticles during charging and discharging processes [187]. Yu et al. demonstrated C/Sn composites with core-shell structure [182,188], and they also prepared nanoparticle-dispersed carbon $(\mathrm{Sn} / \mathrm{C})$ fibers by stabilization of electrospun $\mathrm{SnCl}_{4} / \mathrm{PAN}$ fibers and subsequent carbonization at different temperatures [183]. It was observed that the sintering temperature greatly influences the properties of the $\mathrm{Sn} / \mathrm{C}$ anode. These electrodes showed good electrochemical performance especially in reversible capacity. Sn/C composite fibers sintered at $700^{\circ} \mathrm{C}$ show a discharge capacity of $1211.7 \mathrm{mAh} \mathrm{g}^{-1}$ while the material sintered at $850{ }^{\circ} \mathrm{C}$ showed discharge capacity of only $993 \mathrm{mAh} \mathrm{g}^{-1}$. Ji et al. made C/ $\mathrm{Ni}$ [189] and C/Cu [190], and Wang et al. [191] prepared C/Co composite fibers by electrospinning. The obtained electrodes exhibited good electrochemical performance including large reversible capacity, improved cycle performance, and better rate capacity.

Nanosized $\mathrm{NiO}$ [192], $\mathrm{SnO}_{2}$ and $\mathrm{TiO}_{2}$ [193] have been intensively investigated as anode materials. $\mathrm{NiO} / \mathrm{SWCNT}$ [194] and $\mathrm{C} / \mathrm{Mn}_{3} \mathrm{O}_{4}$ [166] composite fibers were also reported. These composite electrodes show good electrical conductivity, rate capability and good cycle performance. $\mathrm{C} / \mathrm{Mn}_{3} \mathrm{O}_{4}$ composite anode showed a discharge capacity of $450 \mathrm{mAh} \mathrm{g}^{-1}$ with very stable cycle performance up to 50 cycles. $\mathrm{CO}_{3} \mathrm{O}_{4}$ electrospun fibers delivered an initial discharge capacity of $1336 \mathrm{mAh} \mathrm{g}^{-1}$, and after 40 cycles, the capacity was maintained at $604 \mathrm{mAh} \mathrm{g}^{-1}$ [195]. The properties of selected anode materials prepared by electrospinning are tabulated in Table 4. Fan et al. [166] used electrospun manganese oxide fibers as the anode for lithium ion batteries and these exhibited a first discharge capacity of $2200 \mathrm{mAh} \mathrm{g}^{-1}$ which is $134 \%$ higher than the theoretical value expected from the formation of $\mathrm{Mn}$ and $\mathrm{LiO}_{2}$ and may be related to the formation of an SEI layer, as suggested for nano-sized $\mathrm{NiO}[200]$.

\subsection{Cathode materials}

The first commercial lithium-ion battery was produced by Sony, Japan in 1991 . Sony used a layered lithium cobalt oxide $\left(\mathrm{LiCoO}_{2}\right)$ as a cathode material and later Goodenough and coworkers introduced spinel based lithium manganese oxide $\left(\mathrm{LiMn}_{2} \mathrm{O}_{4}\right)$ as a green electrode. As an active cathode material $\mathrm{LiFePO}_{4}$ and phospho-oli- vines are gaining increasing attention in recent years as the next generation cathode material, because of its abundance, low cost, environmentally benignity compared to conventional transition metals oxides $\mathrm{Li}-\mathrm{x}-\mathrm{O}_{2}(\mathrm{x}=\mathrm{Ni}, \mathrm{Mn}$, and $\mathrm{Co})$, which provides a relatively high theoretical capacity of $170 \mathrm{mAh} \mathrm{g}^{-1}$ with good cycle performance in Li secondary batteries. However, all these materials have its own disadvantages such as poor electronic conductivity, rate capability, power density and electrode/electrolyte contact when it is employed as cathode materials in lithium ion batteries. Electrospinning opens up the new room to resolve these entire problems. The electrochemical performance of cathode materials greatly depends on their morphologies. Electrospinning has been widely used for preparing cathode materials with architectural morphology such as nanowires [201], nanobelts [202], nanonuggets [203], biaxial [167] and triaxial [204] core-sheath, and hollow fibers [205] to enhance their electrochemical properties. Among the materials available, layered oxide $\mathrm{LiCoO}_{2}$ has high specific energy density, low self-discharge and excellent cycle life and is mostly used as a cathode material in the commercial batteries [206].

Gu et al. [205] developed a $\mathrm{LiCoO}_{2}$ fiber cathode by combining a sol-gel method with electrospinning. The material shows high initial discharge capacity of $182 \mathrm{mAh} \mathrm{g}^{-1}$ which is $30 \%\left(42 \mathrm{mAh} \mathrm{g}^{-1}\right)$ higher than conventional $\mathrm{LiCoO}_{2}$ powder. Unfortunately, after 20 cycles the discharge capacity decreased to $123 \mathrm{mAh} \mathrm{g}^{-1}$. Using coaxial electrospinning, Gu et al. [167] prepared core-shell structure of $\mathrm{LiCoO}_{2}$ cathode with $\mathrm{LiCoO}_{2}$ nanoparticle as core and amorphous $\mathrm{MgO}$ as the shell. The material showed $90 \%$ retention of initial discharge capacity after 40 cycles. The excellent performance of core-shell $\mathrm{LiCoO}_{2} / \mathrm{MnO}$ cathode is attributed to the prevention of the impedance growth by the $\mathrm{MgO}$ shell. However, $\mathrm{LiCoO}_{2}$ is an expensive material and is not environmentally friendly. For this reason, Lu et al. [165] investigated electrospun spinel $\mathrm{Li}_{4} \mathrm{Ti}_{5} \mathrm{O}_{12}$ as a cathode material in lithium ion batteries. The 3D spinel $\mathrm{Li}_{4} \mathrm{Ti}_{5} \mathrm{O}_{12}$ fiber/Li cell voltage profiles were similar to the typical behavior of spinel $\mathrm{Li}_{4} \mathrm{Ti}_{5} \mathrm{O}_{12}$ and they exhibited a discharge capacity of about $192 \mathrm{mAh} \mathrm{g}^{-1}$ at $0.5 \mathrm{C}$ rate with a capacity loss of $1.0 \%$ per cycle. The lithium insertion and extraction process were stable and reversible with the spinel $\mathrm{Li}_{4} \mathrm{Ti}_{5} \mathrm{O}_{12}$ 3D network architecture, and can be expected to have potential application for 3D batteries as a zero strain insertion materials.

$\mathrm{LiMnO}_{2}$ is another high performance cathode material usually employed in lithium-ion batteries. So far only a few reports have been written on the electrospun $\mathrm{LiMnO}_{2}$. Sun et al. [207] reported electrospun $\mathrm{LiMnO}_{2}$ composite fibers. It shows an initial discharge

Table 4

Morphological and electrochemical properties of anode materials prepared by electrospinning.

\begin{tabular}{|c|c|c|c|c|}
\hline Materials & Nanofiber/particle diameter (nm) & Capacity $\left(\mathrm{mAh} \mathrm{g}^{-1}\right)$ & C-rate & Ref. \\
\hline CNF & $200-300$ & 1000 & 0.08 & [168] \\
\hline $\mathrm{CNF}+\mathrm{Si}$ & $150-300$ & 621 & 0.13 & [172] \\
\hline $\mathrm{CNF}+\mathrm{Si}$ & $300-500 \mathrm{CNF}, 50-80 \mathrm{Si}$ & 1060 & 0.01 & [178] \\
\hline $\mathrm{CNF}+\mathrm{Sn}$ & $100-1000$ CNF, 1 Sn & 816 & - & [180] \\
\hline $\mathrm{CNF}+\mathrm{Sn} / \mathrm{SnO}_{x}$ & $50-500 \mathrm{CNF}, 20-40 \mathrm{Sn}$ & 1192 & 0.03 & [181] \\
\hline $\mathrm{CNF}+\mathrm{Sn}$ & $100 \mathrm{Sn}$ & 1156 & 0.1 & [182] \\
\hline $\mathrm{CNF}+\mathrm{Sn}$ & $150-350 \mathrm{CNF}, 30-40 \mathrm{Sn}$ & 1211.7 & 0.025 & [183] \\
\hline $\mathrm{CNF}+\mathrm{Fe}_{3} \mathrm{O}_{4}$ & $350 \mathrm{CNF}, 8-52 \mathrm{Fe}_{3} \mathrm{O}_{4}$ & 623 & 1.73 & [185] \\
\hline $\mathrm{CNF}+\mathrm{MnO}_{\mathrm{x}}$ & $150-200 \mathrm{CNF}, 21-42 \mathrm{MnO}_{x}$ & 650 & - & [186] \\
\hline $\mathrm{CNF}+\mathrm{Ni}$ & $150-200 \mathrm{CNF}, 20 \mathrm{Ni}$ & 795 & 0.13 & [190] \\
\hline $\mathrm{Co}_{3} \mathrm{O}_{4}$ & 200 & 1336 & 0.5 & [195] \\
\hline $\mathrm{SnO}_{2}$ & $50-80$ & 1650 & 0.1 & [197] \\
\hline $\mathrm{SnO}_{2}$ & 220 & 1650 & 0.23 & [198] \\
\hline $\mathrm{TiO}_{2}$ & 60 & 175 & 0.45 & [199] \\
\hline $\mathrm{Li}_{4} \mathrm{Ti}_{5} \mathrm{O}_{12}$ & $100-200$ & 192 & 0.5 & [155] \\
\hline $\mathrm{Mn}_{3} \mathrm{O}_{4}$ & $100-300$ & 2200 & - & [166] \\
\hline $\mathrm{Co}_{3} \mathrm{O}_{4}+\mathrm{C}$ & $200-300$ & 1146 & 0.11 & [184] \\
\hline $\mathrm{Li}_{4} \mathrm{Ti}_{5} \mathrm{O}_{12}+$ Graphene & 1000 & 164 & 0.2 & [196] \\
\hline
\end{tabular}


capacity of $160 \mathrm{mAh}^{-1}$, which is $14 \%$ higher than the commercial material (theoretical capacity $140 \mathrm{mAh} \mathrm{g}^{-1}$ ). After 50 cycles it showed a capacity fade (compared with initial discharge capacity) of $15.3 \%$. As discussed previously, $\mathrm{LiFePO}_{4}$ is considered to be a very promising cathode material for the next generation. The main drawback of $\mathrm{LiFePO}_{4}$ is its lower electronic conductivity and rate capability. Electronic conductivity of this material is improved by carbon coating. There are a few reports on the enhancement of electrochemical properties of $\mathrm{LiFePO}_{4}$ by preparing its composite with carbon using electrospinning [204,208,209]. Very recently carbon coated $\mathrm{LiFePO}_{4}$ nanowires were reported to have $169 \mathrm{mAh} \mathrm{g}^{-1}$ for 100 cycles [209]. Vanadium pentoxide $\left(\mathrm{V}_{2} \mathrm{O}_{5}\right)$ is an attractive candidate for cathode in lithium ion batteries as it exhibits high theoretical capacities $\left(\sim 400 \mathrm{mAh} \mathrm{g}^{-1}\right)$ due to their capability to intercalate nearly $3 \mathrm{Li}^{+}$ions per mole of active material. Conventional bulk $\mathrm{V}_{2} \mathrm{O}_{5}$ powder cathode is limited by slow lithium diffusion rate in the lattice, structural instability with lithium intercalation/deintercalation and low electronic conductivity, leading to inferior battery performance such as low initial capacity, rapid capacity fading and poor rate capability. Very recently Cheah et al. [210] reported a single phase $\mathrm{V}_{2} \mathrm{O}_{5}$ electrospun fiber with improved discharge capacity. The cell study showed a discharge capacity of $230 \mathrm{mAh} \mathrm{g}^{-1}$ for the first cycle and increased capacity of $320 \mathrm{mAh} \mathrm{g}^{-1}$ in the second cycle. After 50 cycles the cell retained $50 \%$ of its initial discharge capacity and $100 \%$ coulombic efficiency. It was emphasized that a simple and versatile method based on electrospinning for fibers could be extended to other energy storage electrode materials such as $\mathrm{LiCO}_{2}, \mathrm{LiMn}_{2} \mathrm{O}_{4}, \mathrm{LiFePO}_{4}$, and $\mathrm{SnO}$ for the application in 3D batteries.

\section{Conclusions and perspectives on future}

The past few years have witnessed tremendous progress in electrospinning and this versatile method of creating polymer-based highly functional and high performance fibers revolutionize the world of advanced materials. The technique is unique and versatile and allows processing of a rich variety of materials to produce fibers with well defined functional nano-structures. The morphologies and internal structures of these fibers can also be tailored by means of various physical and/or chemical methods. The electrospinning setup has been modified to directly generate fibers with core sheath, hollow structures, uniaxially aligned or layer-by-layer stacked films, or as continuous nanofibrous yarns. In addition to the advanced studies on experimental aspects of processing, theoretical studies and modeling have been carried out to make the process more understandable. Essential studies, nevertheless, are still required and many challenges remain to be faced. To date more than 50 polymers have been electrospun to fiberous mat and great challenges remain to electrospinning many other polymers such as conjugated organic polymers or engineering polymers. The design and construction of process equipment for controllable, reproducible, continuous and mass production of electrospun fibers or membranes have to be developed for industrial production and for the manufacture of new products. Moreover, to control the key performance parameters, the clarification of the fundamental electrodynamics of the electrospinning process and correlation with the polymer fluid characteristics must be reliably predicted and utilized.

There are lots of applications of electrospinning in energy storage devices, and many researchers are trying to utilize its potential in energy storage devices such as lithium ion batteries, capacitors or fuel cells. ESMs open many doors in all directions for these materials, for use as electrode or separators in lithium ion batteries. The sol-gel method has been widely used to prepare cathode or anode materials from a rich variety of organic or inorganic mate- rials. Only few studies have been reported on the use of electrospun cathode or anode materials in lithium ion batteries. The capabilities of many well-established techniques such as the solgel method used for the preparation of electrode materials can be greatly enhanced by combining them with electrospinning. All the reported studies in this area show enhanced electrochemical properties due to the exceptional surface to volume ratio and three dimensional open pore structure. In the last few years, our group and many other researchers have demonstrated electrospun membranes for preparing polymer electrolytes. PVDF, its copolymer $\mathrm{P}(\mathrm{VdF}-\mathrm{HFP})$ and PAN are mostly reported on this area, however, many other polymers still remains to be applied. Ceramic materials play an important role in rechargeable batteries, super capacitors, solar cells and fuel cells. Electrospinning provides a remarkably simple and powerful method for generating ceramic or composite fibers with uniform morphology and low surface roughness. Preparation of ceramic materials in the form of fibers may significantly improve the performance of those devices.

The various approaches that have recently been developed for the scientific understanding, engineering control and potential implementation of electrospun fibers from functional materials will provide a new platform for designing electrode materials and electrolytes in lithium ion batteries and a stable and active enzyme immobilization or encapsulation in enzymatic biofuel cells. Electrospun fibers facilitate large surface area for the attachment of enzyme, so they are ideal host for enzyme immobilization with high enzyme loading and activity. Research into the engineering secondary structure has shown that hollow or porous fibers with circular cross-sections are ideal channels for ion transfer and fabrication of liquid electrolytes in lithium batteries and enzyme immobilization in biofuel cells. With more effort from the scientific and engineering community, electrospinning will become one of the most powerful tools for fabricating high performance advanced materials with broad range of functionalities and applications in multidisciplinary areas in the near future. Thanks to the effort of all research groups who made this cutting edge technology capable of processing a rich variety of advanced materials with controlled morphology.

\section{Acknowledgements}

This work was supported by the Industrial Strategic Technology Development Program (10040033) funded by the Ministry of Knowledge Economy (MKE, Korea), and also by the Pioneer Research Center Program through the National Research Foundation of Korea funded by the Ministry of Education, Science and Technology (2009-0082812).

\section{References}

[1] P. Raghavan, J.W. Choi, J.H. Ahn, G. Cheruvally, G.S. Chauhan, H.J. Ahn, C. Nah, J. Power Sources 184 (2008) 437.

[2] P. Raghavan, X. Zhao, J.K. Kim, J. Manuel, G.S. Chauhan, J.H. Ahn, C. Nah, Electrochim. Acta 54 (2008) 228.

[3] X. Li, G. Cheruvally, J.K. Kim, J.W. Choi, J.H. Ahn, K.W. Kim, H.J. Ahn, J. Power Sources 167 (2007) 491.

[4] G. Cheruvally, J.K. Kim, J.W. Choi, J.H. Ahn, Y.J. Shin, J. Manuel, P. Raghavan, K.W. Kim, H.J. Ahn, D.S. Choi, C.E. Song, J. Power Sources 172 (2007) 863.

[5] J.K. Kim, G. Cheruvally, X. Li, J.H. Ahn, K.W. Kim, H.J. Ahn, J. Power Sources 178 (2008) 815

[6] A. Formhals, US patent 1975504, 1934.

[7] D.H. Reneker, I. Chun, Nanotechnology 7 (1996) 216.

[8] P.H. Tsou, C.K. Chou, S.M. Saldana, M.C. Hung, J. Kameoka, Nanotechnology 19 (2008) 445714

[9] H. Li, Y. Ke, Y. Hu, J. Appl. Polym. Sci. 99 (2006) 1018.

[10] M. Ikegame, K. Tajima, T. Aida, Angew. Chem. Int. Ed. 42 (2003) 2154

[11] P.X. Ma, R. Zhang, J. Biomed. Mater. Res. Part A 46 (1999) 60.

[12] C.J. Ellison, A. Phatak, D.W. Giles, C.W. Macosko, F.S. Bates, Polymer 48 (2007) 3306.

[13] Z. Yang, B. Xu, J. Mater. Chem. 17 (2007) 2385. 
[14] X. Feng, G. Yang, Q. Xu, W. Hou, J.J. Zhu, Macromol. Rapid Commun. 27 (2006) 31.

[15] Y. Hong, R.L. Legge, S. Zhang, P. Chen, Biomacromolecules 4 (2003) 1433.

[16] J. Doshi, D.H. Reneker, J. Electrostat. 35 (1995) 151.

[17] Z.M. Huang, Y.Z. Zhang, M. Kotaki, S. Ramakrishna, Compos. Sci. Technol. 63 (2003) 2223

[18] D. Li, Y. Xia, Adv. Mater. 16 (2004) 1151

[19] A.I. Gopalan, P. Santhosh, K.M. Manesh, J.H. Nho, S.H. Kim, C.G. Hwang, K.P. Lee, J. Membr. Sci. 325 (2008) 683.

[20] Y.H. Liao, D.Y. Zhou, M.M. Rao, W.S. Li, Z.P. Cai, Y. Liand, C.L. Tan, J. Power Sources 189 (2009) 139.

[21] J.W. Choi, G. Cheruvally, Y.H. Kim, J.K. Kim, J. Manuel, P. Raghavan, J.H. Ahn, K.W. Kim, H.J. Ahn, D.S. Choi, C.E. Song, Solid State Ionics 178 (2007) 1235.

[22] S. Zarkoob, R.K. Eby, D.H. Reneker, S.D. Hudson, D. Ertleya, W.W. Adams, Polymer 45 (2004) 3973.

[23] B.M. Min, G. Lee, S.H. Kim, Y.S. Nam, T.S. Lee, W.H. Park, Biomaterials 25 (2004) 1289

[24] W.H. Park, L. Jeong, D.I. Yoo, S. Hudson, Polymer 45 (2004) 7151.

[25] H.J. Jin, J. Chen, V. Karageorgiou, G.H. Altman, D.L. Kaplan, Biomaterials 25 (2004) 1039

[26] S. Sukigara, M. Gandhi, J. Ayutsede, M. Micklus, F. Ko, Polymer 45 (2004) 3701.

[27] B.M. Min, S.W. Lee, J.N. Lim, Y. You, T.S. Lee, P.H. Kang, W.H. Park, Polymer 45 (2004) 7137

[28] A.G. Bailey, Electrostatic Spraying of Liquids, Wiley, New York, 1998.

[29] J.B. Fenn, M. Mann, C.K. Meng, S.F. Wong, C.M. Whitehouse, Science 246 (1989) 64.

[30] I.G. Loscertales, A. Barrero, I. Guerrero, R. Cortijo, M. Marquez, A.M. GaoanCalvo, Science 295 (2002) 1695.

[31] P.J. Hull, J.L. Hutchison, O.V. Salata, P.J. Dobson, Adv. Mater. 9 (1997) 413.

[32] P.K. Baumgarten, J. Colloid Interface Sci. 36 (1971) 71

[33] L. Larrondo, R. Manley, J. Polym. Sci. Polym. Phys. 19 (1981) 921.

[34] L. Larrondo, R. Manley, J. Polym. Sci. Polym. Phys. 19 (1981) 933.

[35] A. Formhals, US patent 2160962, 1939.

[36] A. Formhals, US Patent 2187306, 1940

[37] G.I. Tylor, Proc. Roy. Soc. London A313 (1969) 453

[38] A. Frenot, I.S. Chronakis, Curr. Opin. Colloid Interface Sci. 8 (2003) 64

[39] S. Koombhongse, W. Liu, D.H. Reneker, J. Polym. Sci. Polym. Phys. 39 (2001) 2598.

[40] A. Buer, S.C. Ugbolue, S.B. Warner, Textile Res. J. 71 (2001) 323.

[41] A.G. MacDiarmid, W.E. Jones Jr., I.D. Norris, J. Gao, A.T. Johnson Jr., N.J. Pinto, J. Hone, B. Han, F.K. Ko, H. Okuzaki, M. Llaguno, Synth. Met. 119 (2001) 27.

[42] S.A. Theron, E. Zussmana, A.L. Yarin, Polymer 45 (2004) 2017.

[43] M.M. Demir, I. Yilgor, E. Yilgor, B. Erman, Polymer 43 (2002) 3303.

[44] Y.M. Shin, M.M. Hohman, M.P. Brenner, G.C. Rutledge, Polymer 42 (2001) 9955.

[45] K.H. Lee, H.Y. Kim, H.J. Bang, Y.H. Jung, S.G. Lee, Polymer 44 (2003) 4029

[46] X.H. Zong, K. Kim, D.F. Fang, S.F. Ran, B.S. Hsiao, B. Chu, Polymer 43 (2002) 4403.

[47] W.K. Son, J.H. Youk, T.S. Lee, W.H. Park, Polymer 45 (2004) 2959

[48] A. Koski, K. Yim, S. Shivkumar, Mater. Lett. 58 (2004) 493.

[49] R. Kessick, J. Fenn, G. Tepper, Polymer 45 (2004) 2981.

[50] M. Hohman, M. Shin, G. Rutledge, M.P. Brenner, Phys. Fluids 13 (2001) 2221.

[51] P. Raghavan, J. Manuel, X. Zhao, D.S. Kim, J.H. Ahn, C. Nah, J. Power Sources 196 (2011) 6742

[52] P. Carol, P. Ramakrishnan, B. John, G. Cheruvally, J. Power Sources 196 (2011) 10156.

[53] H.R. Jung, D.H. Ju, W.J. Lee, X. Zhang, R. Kotek, Electrochim. Acta 54 (2009) 3630.

[54] J.S. Stephens, D.B. Chase, J.F. Rabolt, Macromolecules 37 (2004) 877.

[55] X.H. Qin, Y.Q. Wan, J.H. He, J. Zhang, J.Y. Yu, S.Y. Wang, Polymer 45 (2004) 6409.

[56] D. Li, Y. Wang, Y. Xia, Nano Lett. 3 (2003) 1167

[57] E.R. Kenawy, J.M. Layman, J.R. Watkins, G.L. Bowlin, J.A. Matthews, D.G. Simpson, G.E. Wnek, Biomaterials 24 (2003) 907.

[58] S.S. Choi, Y.S. Lee, C.W. Joo, S.G. Lee, J.K. Park, K.S. Han, Electrochim. Acta 50 (2004) 339.

[59] J. Ayutsede, M. Gandhi, S. Sukigara, M. Micklus, H.E. Chen, F. Ko, Polymer 46 (2005) 1625

[60] Z.M. Huang, Y.Z. Zhang, S. Ramakrishna, C.T. Lim, Polymer 45 (2004) 5361.

[61] A.L. Yarin, E. Zussman, Polymer 45 (2004) 2977.

[62] J. Kameoka, H.G. Craighead, Appl. Phys. Lett. 83 (2003) 371.

[63] C.L. Casper, J.S. Stephens, N.G. Tassi, D.B. Chase, J.F. Rabolt, Macromolecules 37 (2004) 573.

[64] Q.B. Yang, D.M. Li, Y.L. Hong, Z.Y. Li, C. Wang, S.L. Qiu, Y. Wei, Synth. Met. 137 (2003) 973.

[65] B. Ding, J. Kim, Y. Miyazaki, S. Shiratori, Sens. Actuators B 101 (2004) 373.

[66] Y. Zhang, Z.M. Huang, X. Xu, C.T. Lim, S. Ramakrishna, Chem. Mater. 16 (2004) 3406.

[67] E.R. Kenawy, G.L. Bowlin, K. Mansfield, J. Layman, D.G. Simpson, E.H. Sanders, G.E. Wnek, J. Controlled Release 81 (2002) 57.

[68] F. Yang, R. Murugan, S. Wang, S. Ramakrishna, Biomaterials 26 (2005) 2603.

[69] N.J. Pinto, P. Carrion, J.X. Quinones, Mater. Sci. Eng. A366 (2004) 1.

[70] P. Gupta, S.R. Trenor, T.E. Long, G.L. Wilkes, Macromolecules 37 (2004) 9211.

[71] K.J. Pawlowski, H.L. Belvin, D.L. Raney, J. Su, J.S. Harrison, E.J. Siochi, Polyme 44 (2003) 1309.
[72] C. Kim, Y.J. Kim, Y.A. Kim, Solid State Commun. 132 (2004) 567.

[73] Z. Ma, M. Kotaki, T. Yong, W. He, S. Ramakrishna, Biomaterials 26 (2005) 2527

[74] S.J. Kim, K.M. Shin, S.I. Kim, Scripta Mater. 51 (2004) 31

[75] J.M. Deitzel, J. Kleinmeyer, D. Harris, N.C.B. Tan, Polymer 42 (2001) 261.

[76] D.A. Brune, J. Bicerano, Polymer 43 (2002) 369.

[77] C. Drew, X. Wang, L.A. Samuelson, J. Kumar, J. Macromol. Sci. Part A - Pure Appl. Chem. A40 (2003) 1415.

[78] S. Mangelski, J.S. Stephens, D.B. Chase, J.F. Rabolt, Macromolecules 35 (2002) 8456

[79] H. Fong, I. Chun, D.H. Reneker, Polymer 4 (1999) 4585.

[80] J.M. Deitzel, W. Kosik, S.H. McKnight, N.C.B. Tan, J.M. DeSimone, S. Crette, Polymer 43 (2002) 1025.

81] S.H. Park, C. Kim, K.S. Yang, Synth. Met. 143 (2004) 175

[82] M. Wang, H. Singh, T.A. Hatton, G.C. Rutledge, Polymer 45 (2004) 5505

83] C. Kim, Y.O. Choi, W.J. Lee, K.S. Yang, Electrochim. Acta 50 (2004) 883.

[84] D. Li, Y. Wang, Y. Xia, Adv. Mater. 16 (2004) 361

[85] D. Li, Y. Xia, Nano Lett. 4 (2004) 933.

[86] M. Bongnitzki, T. Frese, S. Steinhart, A. Greiner, J.H. Wendorff, A. Schaper, M. Hellwig, Polym. Eng. Sci. 41 (2001) 982.

[87] M. Bongnitzki, W. Czado, T. Frese, A. Schaper, M. Hellwig, M. Steinhart, A. Greiner, J.H. Wendorff, Adv. Mater. 13 (2001) 70

[88] X. Wang, K. Zhang, M. Zhu, H. Yu, Z. Zhou, Y. Chen, B.S. Hsiao, Polymer 48 (2008) 2755.

[89] Y. Ner, J.G. Grote, J.A. Stuart, G.A. Sotzing, Angew. Chem. Int. Ed. 48 (2009)

[90] S. Cavaliere, V. Salles, A. Brioude, Y. Lalatonne, L. Motte, P. Monod, D. Cornu, P. Miele, J. Nanoparticle Res. 12 (2010) 2735

[91] E. Jo, S. Lee, K.T. Kim, Y.S. Won, H.S. Kim, E.C. Cho, U. Jeong, Adv. Mater. 21 (2009) 968

[92] D. Navarathne, Y. Ner, M. Jain, J.G. Grote, G.A. Sotzing, Mater. Lett. 65 (2010) 219.

[93] R. Ramaseshan, S. Sundarrajan, R. Jose, S. Ramakrishna, J. Appl. Phys. 102 (2007) 111101

[94] I.S. Chronakis, J. Mater. Process. Technol. 167 (2005) 283.

[95] S.A. Theron, E. Zussman, A.L. Yarin, Polymer 45 (2004) 2017

[96] N. Bhardwaj, S.C. Kundu, Biotechnol. Adv. 28 (2010) 325

[97] W.E. Teo, S. Ramakrishna, Nanotechnology 17 (2006) R89.

[98] L.S. Carnell, E.J. Siochi, R.A. Wincheski, N.M. Holloway, R.L. Clark, Scripta Mater. 60 (2009) 359.

[99] Q. Yu, M. Wang, H. Chen, Mater. Lett. 64 (2010) 428.

[100] Z. Sun, E. Zussman, A.L. Yarin, J.H. Wendorff, A. Greiner, Adv. Mater. 15 (2003) 1929.

[101] Y. Zhao, X. Cao, L. Jiang, J. Am. Chem. Soc. 129 (2007) 764.

[102] T. Zhao, Z. Liu, K. Nakata, S. Nishimoto, T. Murakami, Y. Zhao, L. Jiang, A. Fujishima, J. Mater. Chem. 20 (2010) 5095.

[103] J.T. McCann, D. Li, Y. Xia, J. Mater. Chem. 15 (2005) 735

[104] P. Raghavan, X. Zhao, C. Shin, D.H. Baek, J.W. Choi, J. Manuel, M.Y. Heo, J.H. Ahn, C. Nah, J. Power Sources 195 (2010) 6088.

[105] P.D. Dalton, J.L. Calvet, A. Mourran, D. Klee, M. Möller, Biotechnol. J. 1 (2006) 998.

[106] K.J. Pawlowski, T.L. St. Clair, A.C. McReynolds, C. Park, Z. Ounaies, E.J. Siochi, J.S. Harrison, "Electrospun Electroactive polymers for Aerospace Applications" 44th AIAA/ASME/ASCE/AHS/ASC Structures, Structural Dynamics, and Materials Conference, Norfolk, VA, USA, 2003.

[107] D. Annies, A. Bornat, R.O. Edwards, A. Higham, B. Loveday, J. Wilson, Trans. Am. Soc. Artif. Intern. Organs 24 (1978) 209.

[108] P.K. Kahol, N.J. Pinto, Synth. Met. 140 (2004) 269.

[109] Z. Chen, M.D. Foster, W. Zhou, H. Fong, D.H. Renker, Macromolecules 34 (2001) 6156.

[110] L. Huang, R.A. McMillan, R.P. Apkarian, B. Pourdeyhimi, V.P. Conticello, E.L. Chaikof, Macromolecules 33 (2000) 2989.

[111] B. Ding, E. Kimura, T. Sato, S. Fujita, S. Shiratori, Polymer 45 (2004) 1895

[112] J. Zeng, X. Xu, X. Chen, Q. Liang, X. Bian, L. Yang, X. Jing, J. Controlled Release 92 (2003) 227.

[113] H. Yoshimoto, Y.M. Shin, H. Terai, J.P. Vacanti, Biomaterials 24 (2003) 2077.

[114] K. Kim, M. Yu, X. Zong, J. Chiu, D. Fang, Y.S. Seo, B.S. Hsiao, B. Chu, M. Hadjiargyrou, Biomaterials 24 (2003) 4977.

[115] Y.K. Luu, K. Kim, B.S. Hsiao, B. Chu, M. Hadjiargyrou, J. Controlled Release 89 (2003) 341

[116] X. Zong, S. Ran, D. Fang, B.S. Hsiao, B. Chu, Polymer 44 (2003) 4959.

[117] K. Sawicka, P. Gouma, S. Simon, Sens. Actuators B 108 (2005) 585.

[118] P. Gibson, H.L. Schreuder, D. Rivin, AIChE J. 45 (1999) 190.

[119] P.P. Tsai, H. Gibson, P. Gibson, J. Electrostat 54 (2002) 333.

[120] S. Madhugiri, W. Zhou, J.P. Ferraris, K.J. Balkus Jr., Micropor. Mesopor. Mater. 63 (2003) 75 .

[121] H. Fong, W. Liu, C. Wang, R.A. Vaia, Polymer 43 (2002) 775.

[122] P. Raghavan, X. Zhao, J. Manuel, G.S. Chauhan, J.H. Ahn, H.S. Ryu, H.J. Ahn, K.W. Kim, C. Nah, Elecetrochim. Acta 55 (2010) 1347.

[123] F.M. Gray, Solid Polymer Electrolytes-Fundamentals and Technological Applications, VCH, New York, 1991.

[124] B. Scrosati, Applications of Electroactive Polymers, Chapman Hall, London, 1993.

[125] F.M. Gray, Polymer Electrolytes, RSC Materials Monographs, Cambridge, Roy. Soc. Chem., 1997. 
[126] J.R. MacCallum, C.A. Vincent, Polymer Electrolytes Reviews - I, Elsevier, London, 1987.

[127] J.R. MacCallum, C.A. Vincent, Polymer Electrolytes Reviews - II, Elsevier, London, 1987.

[128] D.E. Fenton, J.M. Parker, P.V. Wright, Polymer 14 (1973) 589.

[129] D.F. Shriver, P.G. Bruce, Solid state electrochemistry, Cambridge, 1995

[130] C.Y. Chiang, M.J. Reddy, P.P. Chu, Solid State Ionics 175 (2004) 631.

[131] Y.J. Wang, D. Kim, Electrochim. Acta 52 (2007) 3181

[132] V. Gentili, S. Panero, P. Reale, B. Scrosati, J. Power Sources 170 (2007) 185.

[133] M. Stolarska, L. Niedzicki, R. Borkowska, A. Zalewska, W. Wieczorek, Electrochim. Acta 53 (2007) 1512.

[134] Z. Li, G. Su, X. Wang, D. Gao, Solid State Ionics 176 (2005) 1903.

[135] D. Shanmukaraj, R. Murugan, J. Power Sources 149 (2005) 90.

[136] N.T.K. Sundaram, A. Subramania, Electrochim. Acta 52 (2007) 4987.

[137] G. Jiang, S. Maeda, H. Yang, Y. Saito, S. Tanase, T. Sakai, J. Power Sources 141 (2005) 143.

[138] Z. Wang, Z. Tang, Mater. Chem. Phys. 82 (2003) 16.

[139] J.M. Tarascon, A.S. Gozdz, C. Schmutz, F. Shokoohi, P.C. Warren, Solid State Ionics 86-88 (1996) 49.

[140] J.W. Choi, J.H. Kim, G. Cheruvally, J.H. Ahn, K.W. Kim, H.J. Ahn, J.U. Kim, J. Ind. Eng. Chem. 12 (2006) 939.

[141] A. Subramania, N.T. Kalyanasundaram, G. Vijayakumar, J. Power Sources 153 (2006) 177.

[142] J. Saunier, F. Alloin, J.Y. Sanchez, G. Caillon, J. Power Sources 119-121 (2003) 454.

[143] W. Pu, X. He, L. Wang, C. Jiang, C. Wan, J. Membr. Sci. 272 (2006) 11.

[144] J.W. Choi, J.K. Kim, G. Cheruvally, J.H. Ahn, H.J. Ahn, K.W. Kim, Electrochim. Acta 52 (2007) 2075.

[145] V. Arcella, A. Sanguineti, E. Quartarone, P. Mustarelli, J. Power Sources 81 (1999) 790.

[146] F. Boudin, X. Andrieu, C. Jehoulet, I.I. Olsen, J. Power Sources 81 (1999) 804.

[147] H. Wang, H. Huang, S.L. Wunder, J. Electrochem. Soc. 147 (2000) 2853.

[148] P. Raghavan, X. Zhao, J. Manuel, C. Shin, M.Y. Heo, J.H. Ahn, H.S. Ryu, H.J. Ahn, J.P. Noh, G.B. Cho, Mater. Res. Bull. 45 (2010) 362.

[149] S.W. Choi, J.R. Kim, Y.R. Ahn, S.M. Jo, E.J. Cairns, Chem. Mater. 19 (2007) 104.

[150] S.W. Choi, S.M. Jo, W.S. Lee, Y.R. Kim, Adv. Mater. 15 (2003) 2027.

[151] J.R. Kim, S.W. Choi, S.M. Jo, W.S. Lee, B.C. Kim, Electrochim. Acta 50 (2004) 69.

[152] S.W. Lee, S.W. Choi, S.M. Jo, B.D. Chin, D.Y. Kim, K.Y. Lee, J. Power Sources 163 (2006) 41.

[153] K. Gao, X. Hu, C. Dai, Y. Tingfeng, Mater. Sci. Eng. B: Mater. Adv. Technol. 131 (2006) 100.

[154] X. He, Q. Shi, X. Zhou, C. Wan, C. Jiang, Electrochim. Acta 51 (2005) 1069.

[155] J.R. Kim, S.W. Choi, S.M. Jo, W.S. Lee, B.C. Kim, J. Electrochem. Soc. 152 (2005) A295.

[156] J.K. Kim, G. Cheruvally, J.W. Choi, J.H. Ahn, D.S. Choi, C.E. Song, J. Electrochem. Soc. 154 (2007) A839.

[157] K.U. Jeong, H.D. Chae, C. Il Lim, H.K. Lee, J.H. Ahn, C. Nah, Polym. Int. 59 (2010) 249.

[158] F. Croce, G.B. Appetecchi, L. Persi, B. Scrosati, Nature 394 (1998) 456.

[159] F. Croce, R. Curini, A. Martinelli, L. Persi, F. Ronci, B. Scrosati, R. Caminiti, J. Phys. Chem. B 103 (1999) 10632.

[160] S.W. Choi, J.R. Kim, S.M. Jo, W.S. Lee, Y.R. Kim, J. Electrochem. Soc. 152 (2005) A989.

[161] T.H. Cho, T. Saki, S. Tanase, K. Kimura, Y. Kondo, T. Tarao, M. Tanaka, Electrochem. Solid State Lett. 10 (2007) A159.

[162] T.H. Cho, M. Tanaka, H. Onishi, Y. Kondo, T. Nakamura, H. Yamazaki, S. Tanase, T. Sakai, J. Power Sources 181 (2008) 155.

[163] Y.W. Ju, J.H. Park, H.R. Jung, W.J. Lee, Electrochim. Acta 52 (2007) 4841.

[164] R. Prasanth, V. Aravindan, M. Srinivasan, J. Power Sources 202 (2012) 299.

[165] H.W. Lu, W. Zeng, Y.S. Li, Z.W. Fu, J. Power Sources 164 (2007) 874.

[166] Q. Fan, M.S. Whittingham, Elecrochem. Solid State Lett. 10 (2007) A48

[167] Y.X. Gu, D.R. Chen, X.L. Jiao, F.F. Liu, J. Mater. Chem. 17 (2007) 1769.

[168] C. Kim, K.S. Yang, M. Kojima, K. Yoshida, Y.J. Kim, Y.A. Kim, M. Endo, Adv. Funct. Mater. 16 (2006) 2393.

[169] A. Manthiram, A. Vadivel Murugan, A. Sarkar, T. Muraliganth, Energy Environ. Sci. 1 (2008) 621.
[170] Y. Wang, G. Cao, Adv. Mater. 20 (2008) 2251.

[171] M. Yoshio, H.Y. Wang, K. Fukuda, Y. Hara, Y. Adachi, J. Electrochem. Soc. 147 (2000) 1245

[172] L. Ji, Y. Yao, O. Toprakci, Z. Lin, Y. Liang, Q. Shi, A.J. Medford, C.R. Millns, X. Zhang. J. Power Sources 195 (2010) 2050

[173] L.W. Ji, X.W. Zhang, Nanotechnology 20 (2009) 155705

[174] L.W. Ji, X.W. Zhang, Electrochem. Commun. 11 (2009) 684.

[175] L.W. Ji, Z. Lin, A.J. Medford, X.W. Zhang, Carbon 47 (2009) 3346.

[176] M.N. Obrovac, L. Christensen, Electrochem. Solid State Lett. 7 (2004) A93.

[177] L. Wang, C.X. Ding, L.C. Zhang, H.W. Xu, D.W. Zhang, T. Cheng, C.H. Chen, J. Power Sources 195 (2010) 5052.

[178] H.S. Choi, J.G. Lee, H.Y. Lee, S.W. Kim, C.R. Park, Electrochim. Acta 56 (2010) 790.

[179] J.M. Tarascon, M. Armand, Nature 414 (2001) 359.

[180] L. Zou, L. Gan, F. Kang, M. Wang, W. Shen, Z. Huang, J. Power Sources 195 (2010) 1216

[181] L. Zou, L. Gan, R. Lv, M. Wang, Z.H. Huang, F. Kang, W. Shen, Carbon 49 (2011) 89.

[182] Y. Yu, L. Gu, C. Wang, A. Dhanabalan, P.A. van Aken, J. Maier, Angew. Chem. Int. Ed. 48 (2009) 6485.

[183] Y. Yu, Q. Yang, D. Teng, X. Yang, S. Ryu, Electrochem. Comm. 12 (2010) 1187.

[184] P. Zhang, Z.P. Guo, Y. Huang, D. Jia, H.K. Liu, J. Power Sources 196 (2011) 6987.

[185] L. Wang, Y. Yu, P.C. Chen, D.W. Zhang, C.H. Chen, J. Power Sources 183 (2008) 717.

[186] Z. Lin, L. Ji, M.D. Woodroof, X. Zhang, J. Power Sources 195 (2010) 5025

[187] K.T. Lee, Y.S. Jung, S.M. Oh, J. Am. Chem. Soc. 125 (2003) 5652.

[188] Y. Yu, L. Gu, C.B. Zhu, P.A. van Aken, J. Maier, J. Am. Chem. Soc. 131 (2009) 15984.

[189] L.W. Ji, Z. Lin, A.J. Medford, X.W. Zhang, Chem. A - Eur. J. 15 (2009) 10718.

[190] L.W. Ji, Z. Lin, R. Zhou, Q. Shi, O. Toprakci, A.J. Medford, C.R. Millns, X.W. Zhang, Electrochim. Acta 55 (2010) 1605.

[191] L. Wang, Y. Yu, P.C. Chen, C.H. Chen, Scripta Mater. 58 (2008) 405.

[192] P. Poizot, S. Laruelle, S. Grugeon, L. Dupont, J.M. Tarascon, Nature 407 (2000) 496.

[193] D. Deng, M.G. Kim, J.Y. Lee, J. Cho, Energy Environ. Sci. 2 (2009) 818.

[194] H.W. Lu, D. Li, K. Sun, Y.S. Li, Z.W. Fu, Solid State Sci. 11 (2009) 982

[195] Y. Ding, P. Zhang, Z. Long, Y. Jiang, J. Huang, W. Yan, G. Liu, Mater. Lett. 62 (2008) 3410.

[196] N. Zhu, W. Liu, M. Xue, Z. Xie, D. Zhao, M. Zhang, J. Chen, T. Cao, Electrochim. Acta 55 (2010) 5813

[197] Z. Yang, G. Du, C. Feng, S. Li, Z. Chen, P. Zhang, Z. Guo, X. Yu, G. Chen, S. Huang, H. Liu, Electrochim. Acta 55 (2010) 5485.

[198] L. Li, X. Yin, S. Liu, Y. Wang, L. Chen, T. Wang, Electrochem. Commun. 12 (2010) 1383.

[199] M.V. Reddy, R. Jose, T.H. Teng, B.V.R. Chowdari, S. Ramakrishna, Electrochim. Acta 55 (2010) 3109.

[200] L. Yuan, Z.P. Guo, K. Konstantinov, P. Munroe, H.K. Liu, Electrochem. Solid Sate Lett. 9 (2006) A524.

[201] L. Mai, L. Xu, C. Han, X. Xu, Y. Luo, S. Zhao, Y. Zhao, Nano Lett. 10 (2010) 4750.

[202] C. Ban, N.A. Chernova, M.S. Whittingham, Electrochem. Commun. 11 (2009) 522.

[203] A. Le Viet, M.V. Reddy, R. Jose, B.V.R. Chowdari, S. Ramakrishna, Electrochim. Acta 56 (2011) 1518.

[204] E. Hosono, Y. Wang, N. Kida, M. Enomoto, N. Kojima, M. Okubo, H. Matsuda, Y Saito, T. Kudo, I. Honma, H. Zhou, Am. Chem. Soc. Appl. Mater. Interfaces 2 (2009) 212.

[205] Y. Gu, F. Jian, J. Phys. Chem. C 12 (2008) 20176

[206] Y.K. Sun, I.H. Oh, S.A. Hong, J. Mater. Sci. 31 (1996) 3617.

[207] K. Sun, H.W. Lu, D. Li, W. Zeng, Y.S. Li, Z.W. Fu, J. Inorg. Mater. 24 (2009) 357

[208] O. Toprakci, L. Ji, Z. Lin, H.A.K. Toprakci, X. Zhang, J. Power Sources 196 (2011) 7692.

[209] C. Zhu, Y. Yu, L. Gu, K. Weichert, J. Maier, Angew. Chem. Int. Ed. 50 (2011) 6278.

[210] Y.L. Cheah, N. Gupta, S.S. Pramana, V. Aravindan, G. Wee, M. Srinivasan, J. Power Sources 196 (2011) 6465. 